\title{
Use and Conservation of Medicinal Plants by Indigenous People of Gozamin Wereda, East Gojjam Zone of Amhara Region, Ethiopia: An Ethnobotanical Approach
}

\author{
Nigussie Amsalu $\mathbb{D}^{1},{ }^{1}$ Yilkal Bezie $\mathbb{D}^{\mathrm{D}},{ }^{2}$ Mulugeta Fentahun, ${ }^{1}$ \\ Addisu Alemayehu, ${ }^{3}$ and Gashaw Amsalu ${ }^{1}$ \\ ${ }^{1}$ Department of Biology, Debre Markos University, Debre Markos, Ethiopia \\ ${ }^{2}$ Department of Biotechnology, Debre Markos University, Debre Markos, Ethiopia \\ ${ }^{3}$ Department of Chemistry, Debre Markos University, Debre Markos, Ethiopia \\ Correspondence should be addressed to Yilkal Bezie; yilkalb@gmail.com
}

Received 16 September 2017; Accepted 22 January 2018; Published 19 March 2018

Academic Editor: Karin Kraft

Copyright (c) 2018 Nigussie Amsalu et al. This is an open access article distributed under the Creative Commons Attribution License, which permits unrestricted use, distribution, and reproduction in any medium, provided the original work is properly cited.

An ethnobotanical study of medicinal plants (MPs) used by the local community has been carried out from January 5, 2014, to February 15, 2015, in Gozamin Wereda of East Gojjam Zone, Ethiopia. The purpose of this study was to identify and document the use and conservation of MPs, along with indigenous knowledge of Gozamin community. Data were collected using semistructured interview, field observation, and focus group discussions. The collected data were assessed quantitatively using fidelity level, Jaccard's Coefficient of Similarity, paired comparisons, direct matrix, and preference rankings. In total 93 MPs distributed under 51 families and 87 genera were identified and for each taxon a local name (Amharic) was documented. Asteraceae with 9 (9.68\%) species and Solanaceae with 7 (7.53\%) species were families represented by more species in the study area. Out of these MPs collected, 80 plant species were used for the treatment of human ailments, 24 species were used against livestock diseases, and 11 common plant species were listed in both cases. The most frequently used plant parts were the leaves followed by the roots. The major threats to MPs in the study area were agricultural expansion, overgrazing, fire wood collection, mining, and cutting down trees for construction and furniture. Therefore, there is a need for appropriate in situ and ex situ conservation measures.

\section{Introduction}

Findings indicated that Ethiopia is one of the top 25 biodiversity-rich countries in the world and hosts two of the world's 34 biodiversity hotspots, namely, the Eastern Afromontane and the Horn of Africa hotspots [1]. It is also among the countries in the Horn of Africa regarded as major center of diversity and endemism for several plant species [2]. The diverse topography gave rise to a wide range of altitude and other environmental factors that resulted in diversity of life [2-6]. Thus, the country is a land not only of highly varied landscapes and hence flora and fauna, but also of multiplicity of ethnic groups with complex cultural diversity [4].

Ethiopia has diverse medicinal flora distributed in different vegetation types. About 1,000 medicinal plants (MPs) have been identified and documented [7]. The country is also ethnobotanically rich as there are diverse ethnic groups with diverse cultures. The knowledge and skills used in medication have been held by certain families and have passed down orally from parent to children, often a much loved one [4]. For most parts of the centuries, medicinal use knowledge and practices remained oral without documentation. Documentation of those plants used as traditional medicines is needed so that the knowledge can be preserved and utilized sustainably.

The use of traditional medicine is still widespread in Ethiopia, as well as its acceptability, availability, and popularity no doubt since about $90 \%$ of the populations use it for healthcare needs [8]. However, according to Giday and Ameni [9], loss of knowledge has been aggravated by the expansion of modern education, which has made the younger generation underestimates its traditional value. Similar to 
elsewhere in the country, people living in Gozamin Wereda (district) have traditional practices which have passed from generation to generation in order to treat both humans and livestock ailments. The human tendency to categorize and organize knowledge and experience is universal and that emic classification system throughout the world shows certain structural similarities [10].

In spite of the vast role of ethnobotanical contributions of MPs in the primary healthcare, limited works have so far been done in the country so as to document and enhance associated indigenous knowledge (IK) [4, 11-16]. This study has therefore been initiated to study and document plants used in the traditional medical practices of the people of Gozamin Wereda together with ethnobotanical and ethnomedicinal knowledge and practices.

Like all other parts of the country majority of the people of the study Wereda used herbal medicines for a long time to treat human and livestock ailments. Still now the dependence on this medicine is continuing because of its acceptability, accessibility, and affordability. The present study aimed at identification and documentation of MPs and associated knowledge of using, managing, and conserving MPs by the community of Gozamin Wereda which also becomes useful in the introduction of alternative resource management like in situ conservation systems that involve local people which is an urgent task for the study area where its natural vegetation is lost rapidly.

The study also aspires to identify and record the use of medicinal plant species for purposes other than their medicine. Besides, scanty attempts have been made to identify factors associated with their collection, threats, utilization, and use of the plants for the communities. Thus, the research fills this gap by documenting the wealth of indigenous knowledge and understanding the corresponding drivers of this knowledge related to management and conservation of medicinal plants used to treat human and livestock ailments in study area.

\section{Materials and Methods}

\subsection{Description of the Study Area}

2.1.1. Location, Demography, and Boundary. Gozamin Wereda is one of the 18 Weredas in East Gojjam Zone and 151 Weredas in Amhara National Regional State [17]. The relative location of the Wereda is $300 \mathrm{~km}$ away from the capital city of the country, Addis Ababa, and $260 \mathrm{~km}$ from Bahir Dar, the regional capital city. This Wereda is found almost mid-way from Addis Ababa to Bahir Dar. The Wereda is bounded by Senan Wereda in the North, Baso Liben Wereda and Oromia National Regional State in the South, Aneded and Debay Tilatgen Wereda to the East, and Machakle and Debre Elias Wereda in the West [17].

The total population of the Wereda has an estimated size of 173,300 of which 87,178 are males and 86,122 are females: the highest population $(80,294)$ is in the age range of $0-14$ whereas the lowest one is above the age of 60 which accounted for 7,837 in number [17]. 2094 (1.34\%) of the population are urban dwellers which is less than the zonal average of
$11.2 \%$. Moreover with an estimated area of 1,218.07 square kilometers, it has an estimated population density of 128.3 people per square kilometer which is also less than the zonal average of 179.96, East Gojjam Zone Office of Finance and Economic Development [17]. The ethnicity of the Wereda population is Amhara and Amharic is every body's language.

2.2. Geomorphology and Vegetation Type. The topography of the Wereda is characterized by the three major agroclimatic zones within altitude range of 500-3500 meters above sea level: temperate (Dega) (35.55\%), subtropical (Woina Dega) (41.41\%), and tropical (Kolla) $(15.72 \%)$. The Wereda relief in percentage is given as plateau $45 \%$, mountain $48 \%$, and valley $7 \%$. With respect to soil type, the majority of the Wereda soil belongs to vertisol and lithosol [17].

The vegetation type of Gozamin could be Dry Evergreen Afromontane Forest. According to Friis et al. [18], Dry Evergreen Afromontane Forest (DAF) and grassland complex occurs in areas between 1800 and 3000 meters of altitude with rainfall $<1700 \mathrm{~mm}$. Different authors also indicated the subtypes of DAF, namely, undifferentiated Afromontane Forest; dry single-dominant Afromontane Forest of the Ethiopian highlands; Afromontane woodland, wood grassland and grassland, and transition between Afromontane vegetation and Acacia-Commiphora Bushland on the Eastern Escarpments. The natural vegetation of the study area is dominated by remnant trees like Juniperus procera, Hagenia abyssinica, Podocarpus falcatus, Acacia abyssinica, Cordia africana, Ficus sycomorus, Erythrina brucei, Eucalyptus camaldulensis, Eucalyptus globulus, and others. Plantations of these trees are observed on farm lands and home-gardens in Wereda [17].

There is also an Afroalpine belt as long as the Wereda includes a particular subdistrict (Kebele) known as Gedellamma which is in the Choke mountain system. It is clearly indicated that mountains are virtually devoid of vegetation and the only few woody plant species observed are moorland types sparsely covered with Giant Lobelia (Lobelia rhynchopetalum), lady's mantle (Alchemilla humania), Guassa grass (Festuca spp.), and other grasses. The woody plant cover includes Erica arborea and Giant St. John's wort (Hypericum revolutum) [19].

The rainfall pattern is unimodal, stretching from May to September. The highest monthly rainfalls were record in July, $284.67 \mathrm{~mm}$, and August, $298.03 \mathrm{~mm}$, and the lowest ones were observed in January (14.52 $\mathrm{mm})$ and February $(10.6 \mathrm{~mm})$. The mean annual rain fall distribution is $1342 \mathrm{~mm}$. The mean annual maximum and minimum temperature records of the study site were $26^{\circ} \mathrm{C}$ and $8.6^{\circ} \mathrm{C}$, respectively. Rainy months are blackened and dry months are dotted as indicated in Figure 2.

2.3. Health. The most important animal diseases in Gozamin Wereda include bacterial infections (black leg, pasteurellosis, anthrax, mastitis, fowl typhoid, and avian salmonellosis), endoparasites (fascioliasis, paramphistomiasis, and strongyloidiasis), ectoparasites (ticks, mites, lice, and insect flies), viral infections (rabies, African horse sickness, and foot and mouth diseases), and protozoal infections (trypanosomiasis, babesiasis, and coccidiosis) [17]. On the other hand, it was also reported that the most common human diseases include 


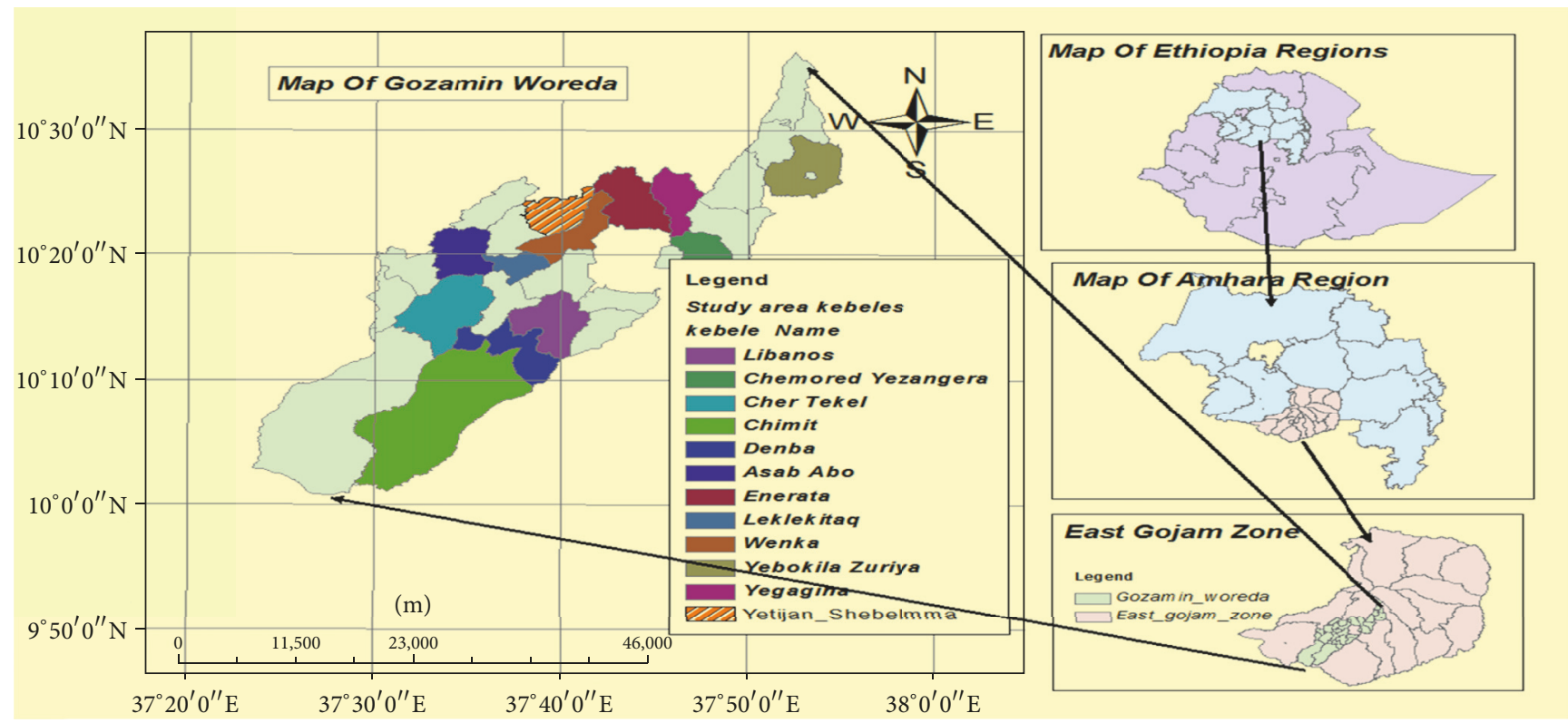

FIGURE 1: Map of Ethiopia showing location of the study area.

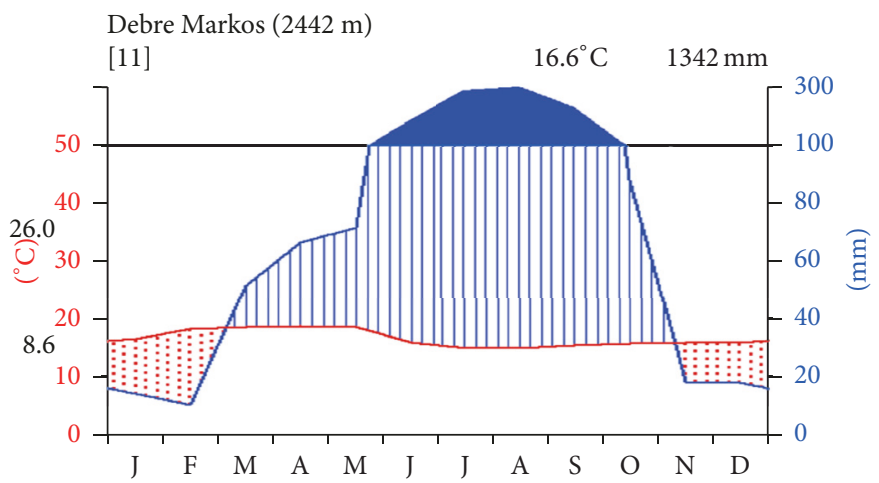

Figure 2: Climadiagrams of the study area from 2005 to 2014 at Debre Markos Station (data source: National Meteorological Agency).

tuberculosis, malaria, diarrhea, trachoma, helminths, skin diseases, typhoid, eye diseases, and upper respiratory tract.

2.4. Reconnaissance Survey. Reconnaissance survey was conducted from September 23 to 30, 2013, in the study Wereda in order to obtain an impression about medicinal plants, topography, distribution of plants, and identification of sampling sites. During the survey 12 representative Kebeles (subdistricts) were selected. Local administrators were chosen as key resource persons in providing information in their respective Kebeles. During the survey, general information about the Wereda was also obtained.

2.5. Site Selection. Purposively twelve Kebeles were selected out of 26 Kebeles of the Wereda for ethnobotanical data collection based on the availability of traditional medicinal practitioners present, identified with the assistance of the Kebele administration leaders, elders, religious leaders, and others who have information about traditional healers. Those Kebeles which have almost the same agroclimatic conditions as other neighboring Kebeles were not included in the study and this is also additional factor for site selection. The study Kebeles were Libanos, Chimbord Yezangera, Cher Tekel, Denba, Asab Abo, Enerata, Lekilekita, Wenka, Chimit, Yegagina, Yebokila Zurya, and Yetijan-Shebelmma (Figure 1).

2.6. Selection of Informants. A total of 100 informants ( 88 males and 12 females) were selected from the representative Kebeles. Representative common informants and knowledgeable traditional medicine practitioners (key informants) of Gozamin Wereda were selected using random and purposive sampling approaches, respectively, following Martin [20].

Out of 100 informants, 80 general informants were sampled during random visits in the study Kebeles by asking every individual in the house or working fields or wherever they were. On the other hand, the remaining 20 key informants out of the total were selected purposively and systematically. In other words, this was based on comments and recommendations from the religious leaders, elders, Kebele administrators, students, and personal observation of the 
researchers from the community group. The selection of key informants was also based on the quality of explanations that particular informants gave during the interview. Local healers automatically qualified as key informants being traditional experts who are custodians of IK on the use of traditional MPs. Thus, key informants were identified, later interviewed, and followed for further details.

2.7. Data Sources. Ethnobotanical data were obtained from both primary and secondary sources. The primary sources were interview, focus group discussion, and observation in the field of the study area, where as the secondary data sources were various and relevant literature review related to the present study. A piece of other information was also collected from the Wereda of different offices.

2.8. Ethnobotanical Data Collection Techniques. The study has been carried out by interviewing the knowledgeable informants in different villages under various sites from January 5, 2014, to February 15, 2015, in Gozamin Wereda, East Gojjam Zone of Amhara Region Ethiopia. Ethnobotanical techniques were employed to collect data on knowledge and management of traditional MPs used by the local people in the study area. The methods used for ethnobotanical data collection were semistructured interviews following Martin [20] and Cotton [10], informant consensus, field observation, and group discussion as described below.

2.8.1. Semistructured Interviews. A list of questions was prepared that was covered in discussion with the informants in a particular order. The interview was guided to cover the key topics on the checklist while leaving room to pursue any relevant subject brought up by the interviewee. All of the interviews were held in Amharic, the language of the local people by the researcher. The place and the time for discussion were set based on the interest of the informants. The status of all the MPs was recorded as abundant, less abundant, rare, or very rare as per healer perception during the semistructured interviews.

2.8.2. Field Observation. Field observations were carried out with local people, guidance, interviewed informants, and students. Habitat, habit, abundance, and distribution of plants were recorded in the given area.

2.8.3. Focus Group Discussion. Short, brief, and precise group discussions were made with informants regarding the MPs in the study sites. Information on local names of the plants, their medicinal uses, methods of preparation, mode of administration, disease conditions, IK on MPs, and threats to plants, conservation and management of plants, and related data were recorded.

2.9. Voucher Specimen Collection. Plants used for herbal remedies were collected by a team comprising a botanist, biotechnologist, microbiologist, chemist, and parasitologist from Debre Markos University (DMU). The voucher specimens were collected at the spot during guided field walk, numbered, pressed, dried, and deep frozen for identification.
Determination of specimens was carried out both in the field and in the herbarium. Then after that, nomenclature was determined using Flora of Ethiopia and Eritrea, other available taxonomic literatures, and visual comparison with authenticated herbarium specimens. Finally, the voucher specimens were kept at Debre Markos University MiniHerbarium to aid confirmation of plant identity.

The information gathered included vernacular name of plant, species, ailments they cure, part used, route of administration, method of preparation, dose, and duration levels of herbal administration. Therefore, this is the starting point of documenting the flora of Gojjam in general and Gozamin Wereda of East Gojjam Zone in particular.

\subsection{Ethnobotanical Data Analysis}

2.10.1. Preference Ranking. Preference ranking was included in predesigned semistructured interview items. It was conducted following Martin [20] for six MPs in treating diseases. The key informants were selected to identify the best preferred MPs for the treatment of ailments based on their personal preference or perceived degree of importance in the community. They were informed to assign the highest value (5) for the most preferred plant species and the lowest value (1) for the least preferred ones. Finally, the values were summed up and the ranks given to each plant.

2.10.2. Direct Matrix Ranking. Direct matrix ranking was conducted following Cotton [10], on six multipurpose MPs. Each key informant assigned items by considering several attributes one at a time, using numerical scale in which the highest number is equal to the most preferred item whereas the lowest one is equal to the least preferred one. Then the informants rated their preferences. Direct matrix ranking can also be done as a group exercise in which participants reach consensus on the ranking of each item or vote according to their individual assessments [20].

2.10.3. Paired Comparison. After having identified five most important MPs based on their medicinal values as perceived by the informants, the paired comparisons were employed following Martin [20]. Paired comparisons on the five most effective plants in treating health problems were conducted using random number table and flipping coins.

2.10.4. Jaccard's Coefficient of Similarity. This can be used to determine the similarity in species composition of the study area with other study areas done by other researchers. Jaccard's Coefficient of Similarity (JCS) was used so as to assess plant species composition similarity, among seven different Weredas. It was computed between the present study area and other areas, which were studied by other authors in different parts of the country. JCS was calculated following Kent and Coker [21].

2.10.5. Fidelity Level (FL). Because many plant species may be used in the same use category, we needed to determine the most preferred species used for the treatment of a particular ailment, and we did so by calculating fidelity levels (FL) [22]: 


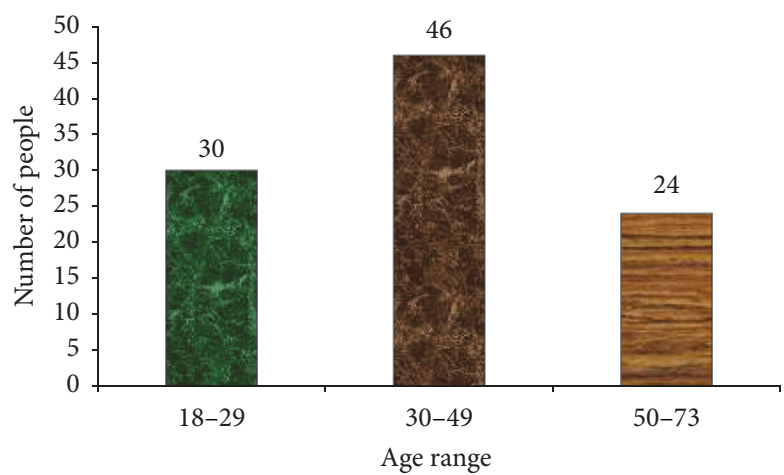

FIgURE 3: Age range of informant.

$\mathrm{FL}=(1 / 4) N p / N$, where $N p$ is the number of use-reports cited for a given species for a particular ailment, $N$ is the total number of use-reports cited for any given species. High FL values (near 100\%) are obtained for plants for which almost all use-reports refer to the same method of use (i.e., the plants were considered the most preferred species for a particular ailment category), whereas low FL are obtained for plants that are reused for many different purposes.

\section{Results and Discussion}

3.1. Summary of Informants. A total of 100 herbalists from the study sites were interviewed and as a result ninety-three (93) plant species belonging to 51 plant families and 87 genera were identified for the management of both human and livestock ailments (Figure 3). The present study has shown that the people at various age groups in Gozamin Wereda have a very good knowledge base on herbal remedy for primary healthcare. Traditional healers (both males and females) still rely largely on naturally growing species in their locality.

3.2. Age and Sex of Informants. The informants were local residents aged between 18-73 years (Figure 3). Most of traditional healers range within the age group of 30-49 years, $46(46 \%)$. They are within this range because it is at this stage whereby they have completed necessary rites of passage, notably initiation school. These are followed by those who are around 18-29 years of age, 30 (30\%), who also constitute a reasonable number; thus in most cases these are newly inaugurated traditional healers. The remaining 24 (24\%) of informants were between the ages of 50 and 73 (Figure 3). Although the age groups 50-73 constitute lower percentage (24), these groups are highly trusted by the community due to experience they have acquired and the number of traditional healers they have trained. Thus, at this age their decisions are credible based on their maturity level. Medicinal plant knowledge difference among age groups was also reported in Cotton [10].

Regarding sex, 88 (88\%) of the total informants were males whereas the remaining $12(12 \%)$ were reported as females (Table 1). In the case of knowledge difference between the two sexes, females tend to mention little number of MPs as compared to males. At this point, because of cultural influence, it is understandable that females were not allowed
TABLE 1: Sociodemography of the informants.

\begin{tabular}{lccc}
\hline Informants & Categories & Number & $\%$ \\
\hline \multirow{3}{*}{ Sex } & Male & 88 & 88.00 \\
& Female & 12 & 12.00 \\
& Total & 100 & 100 \\
\hline Marital status & & & \\
Married & Male & 56 & 56.00 \\
& Female & 10 & 10.00 \\
& Total & 66 & 66.00 \\
Unmarried & Male & 28 & 28.00 \\
& Female & 2 & 02.00 \\
& Total & 30 & 30.00 \\
Divorced & Male & 3 & 03.00 \\
Grand total & Female & 1 & 01.00 \\
Educational level & Total & 4 & 04.00 \\
Modern education & & 100 & 100 \\
Church education & & & \\
Uneducated/illiterate & & 64 & 64.00 \\
Total & & 17 & 17.00 \\
\hline
\end{tabular}

to go out of home; they look after babies and work at home. Similar results were reported in Megersa et al. [23], Kefalew et al. [24], and Chekole et al. [25] mentioning few numbers of plants by females in our study area.

3.3. Educational Level and Marital Status of the Informants. The educational status of the informants showed that most of them were literate, that is, having modern education (diploma holders, students, and those able to read and write) accounting for 64 (64\%) followed by the uneducated ones but traditionally knowledgeable informants accounted for 19 (19\%) and the least number of respondents was reported as church education attendants, 17 (17\%) (Table 1). On the other hand, the marital status of the informants indicated that most of them were married people accounting for 66 (66\%) followed by the unmarried ones, 30 (30\%), and others were divorced, reported as 4 (4\%) (Table 1). The interviewed informants were included from married, unmarried, and divorced people and people of different educational level. This enabled the researchers to come across the ethnobotanical information of the community from different groups. Similar results were also reported by Yineger et al. [26].

3.4. Traditional Knowledge Transfer. The most important way of transfer of IK on types of use of MPs, mode of preparations, way of administration, traditional idea of illnesses, and methods of diagnosis and treatment among indigenous herbal practitioners of Gozamin community was by word of mouth to a family member. The finding further indicated that the present knowledge transfer system followed the inheritance based transfer system where most traditional healers pass their knowledge to the elder/eldest/son/daughter. The selection of the elect was based upon his/her good conduct and ability to keep the secret with regard to the 
ethnobotanical plant use knowledge. The knowledge transfer system is bounded by traditional rules and can only happen through cultural ceremony. Most of the healers confirmed that, during transfer of the knowledge, they also received obligation. Similarly it was also reported that, at family level, it is restricted to the elders (men and women), followed by elder son or daughter or their trustworthy person when the mother or the father is getting old or near to die [14, 27, 28].

\subsection{Medicinal Plants in Gozamin Wereda}

\subsubsection{Plants Used to Treat Human and Livestock Ailments.} In the current study, ninety-three medicinal plant species distributed across 51 families and 87 genera were collected and documented from the study site (Tables 2 and 3). Of the total collected MPs, 80 plant species were used for the treatment of human ailments and 24 species were used against livestock diseases. Eleven (11) common plants species were listed in both which were used to treat both livestock and human ailments (Tables 2 and 3). The finding shows large numbers of MPs were used to treat human diseases compared with livestock ailments. This indicated that local people of the study area give much more priority of traditional medicine for their treatment as compared to their livestock ailments. As a result, they could acquire lower knowledge of MPs to treat livestock ailments than knowledge of MPs treating human ailments. Similar ethnobotanical findings were reported by Megersa et al. [23], Giday et al. [29], Getaneh [30], and Gebeyehu et al. [31].

The ethnobotanical study of MPs in Gozamin Wereda showed that plant medicines are used by a large amount of the population and it is the most important means of treating some common human and livestock ailments such as wound, stomachache, dysentery, diarrhea, gastritis, eczema, eye disease, snakebite, malaria, tapeworm, toothache, evil eye, cough, hemorrhoids, febrile illness, anthrax, control of leech, external animal parasites, tonsillitis, and fever especially for those community members who cannot buy the modern medicines with a relatively higher price.

3.5.2. Diversity of Medicinal Plants in Natural Habitat and Home-Garden. Most medicinal plants were collected in their natural habitat which account for $42(45 \%)$ whereas $28(30 \%)$ medicinal plants were from home-garden and 23 (25\%) were from both home-garden and the wild (Figure 4). Various studies conducted in Ethiopia as well as other countries in the world reported that majority of MPs were harvested from the wild [32-34]. Here, our findings revealed that many MPs were also collected from home-gardens. This indicated that the people and the local healers have started cultivating many MPs in their gardens.

3.5.3. Plant Parts Used in the Study Area. Every part of different plant species is used against a variety of ailments. As per the informant's response, the most commonly used part is the leaf (39), followed by root (16), seed (13), fruit, latex, leaf/or fruit, and stem (4, each) (Figure 5). In some cases, more than one organ of the same plant species, particularly a combination of parts, is used in the preparation of different

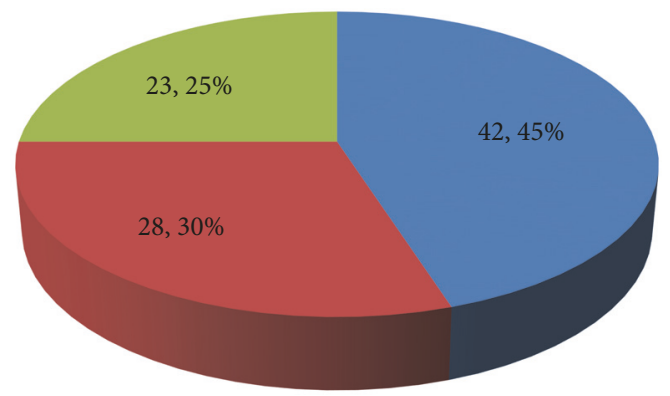

$$
\begin{aligned}
& \text { Habitat } \\
& \text { Wild (natural habitat) } \\
& \text { Home-garden } \\
& \text { Wild and home-garden }
\end{aligned}
$$

FIGURE 4: Diversity of medicinal plants in natural habitat and homegarden.

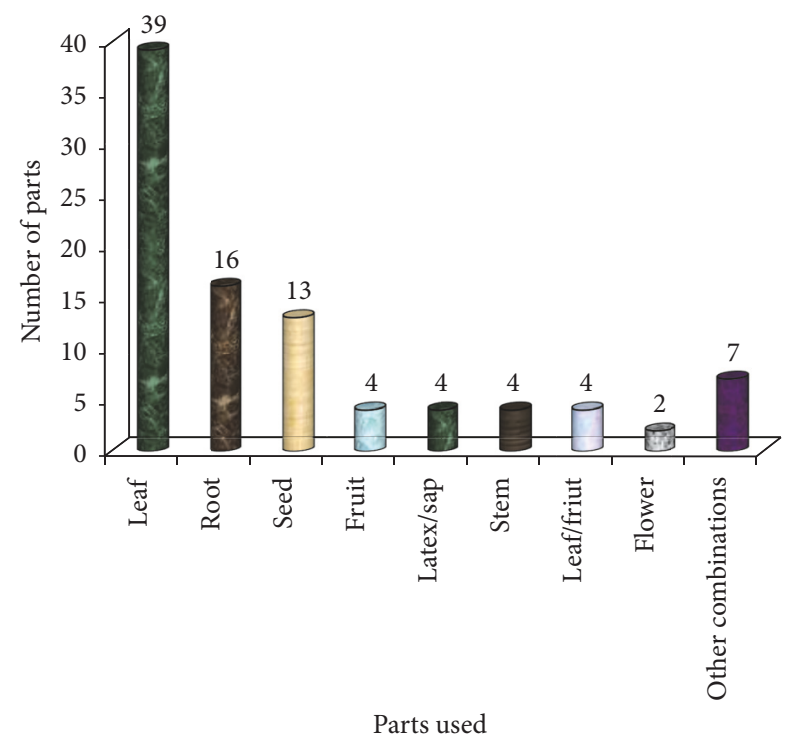

Figure 5: Plant parts used by Gozamin's community.

therapies (see also Tables 2 and 3). It was also observed that the indigenous people have deep knowledge and ageold experience in the right mix of different plant parts to get better treatment of the given ailment. In this study, leaves are the most frequently utilized part of plant organs. Analogous results on different ethnobotanical studies by Giday et al. [12], Megersa et al. [23], Kefalew et al. [24], Gebeyehu et al. [31], Tolasa [32], and Lulekal et al. [33] were reported in Ethiopia.

It was reported that the ease of accessibility to leaves explains their frequent inclusion in most of the preparations [35]. It was also observed that residents have been using leaves to identify MPs. Additionally, leaves are the main photosynthetic organs in plants, and photosynthates are translocated to other parts, such as the root, stem, fruit, and seed. These can act as toxins for protection of predators and some are of medicinal value to humans.

On the other hand, the results of the study showed that harvesting of roots has great impact on the plants and leads to 


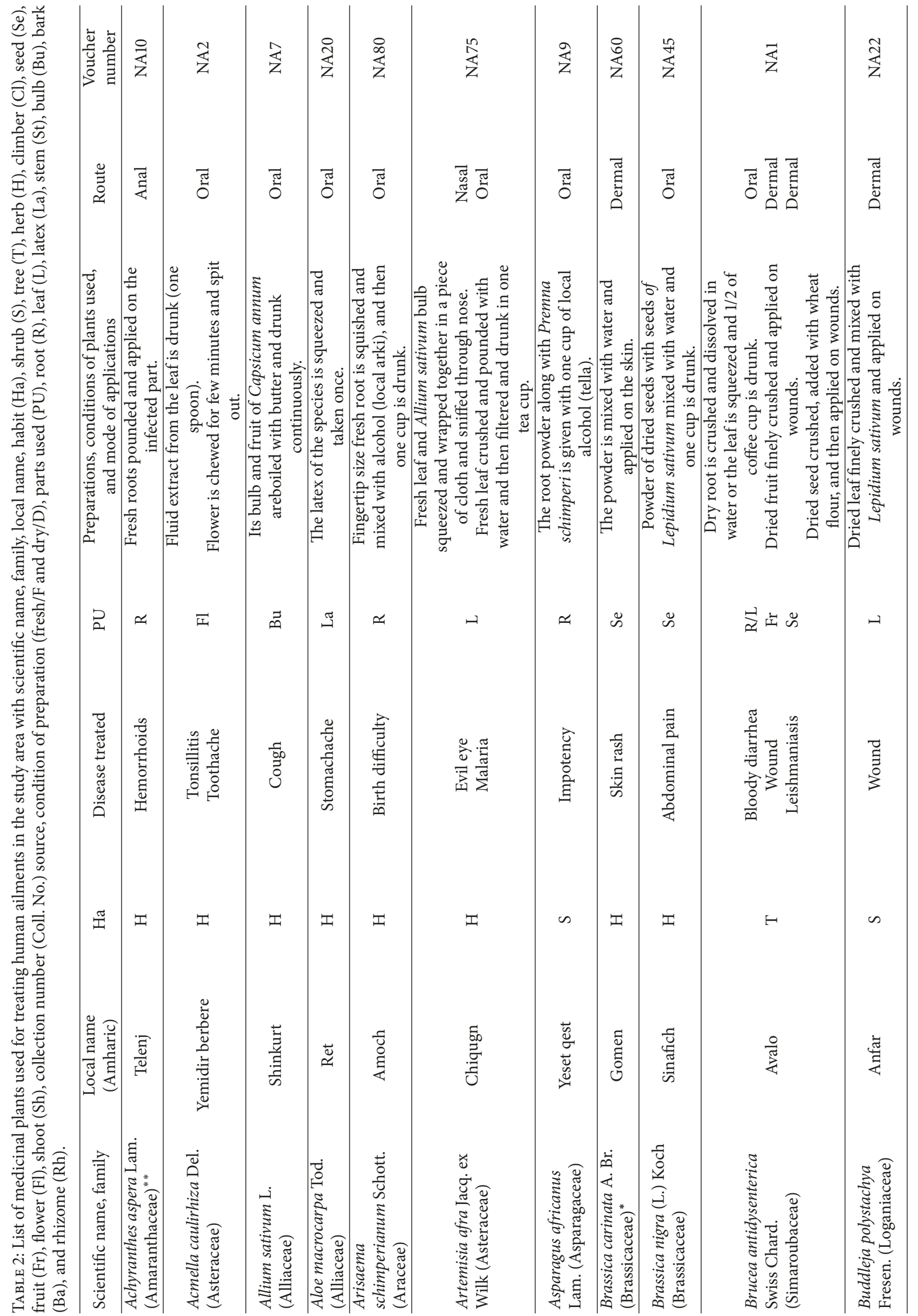




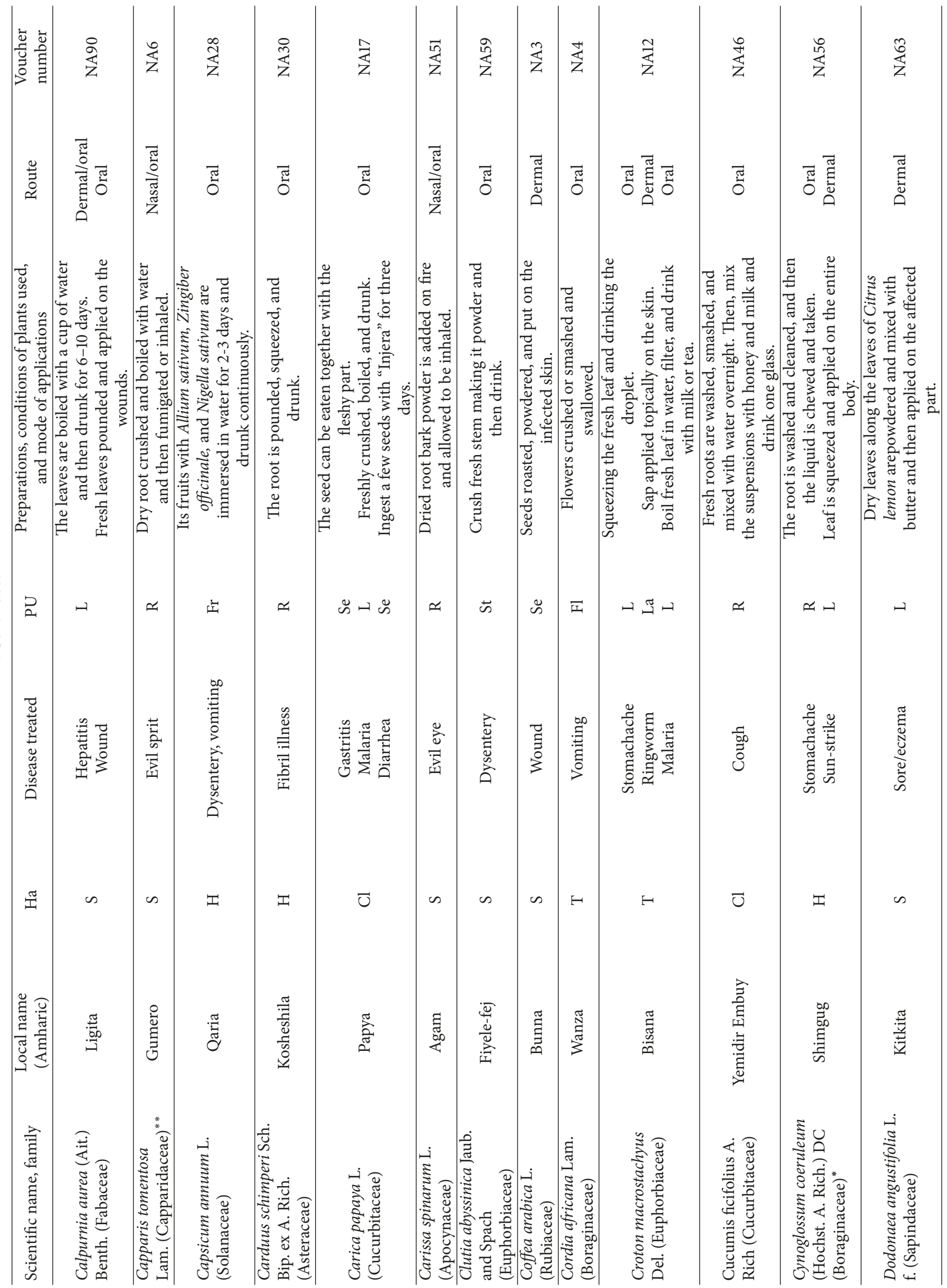




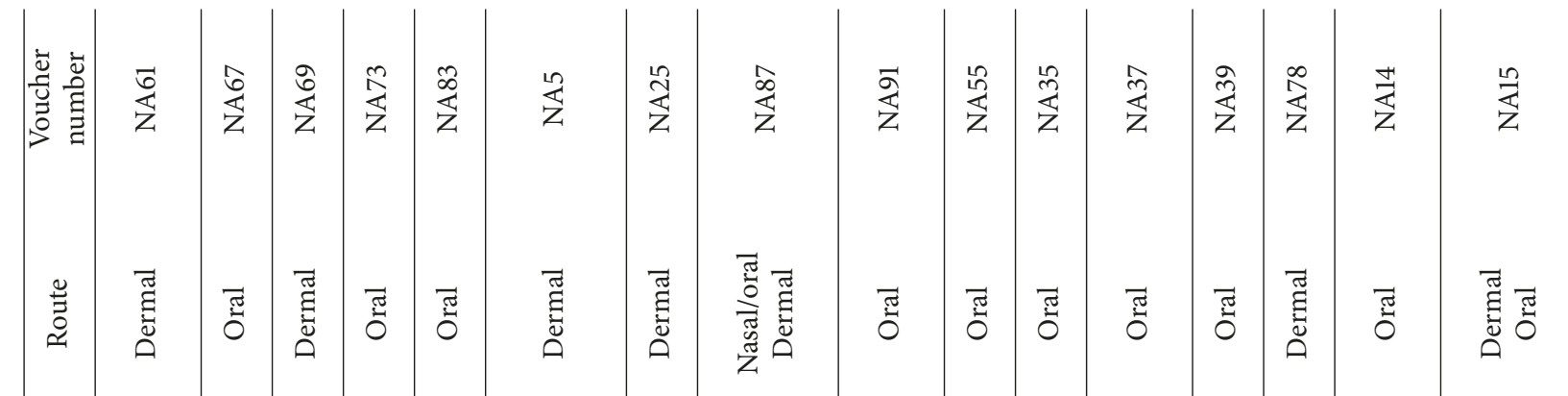

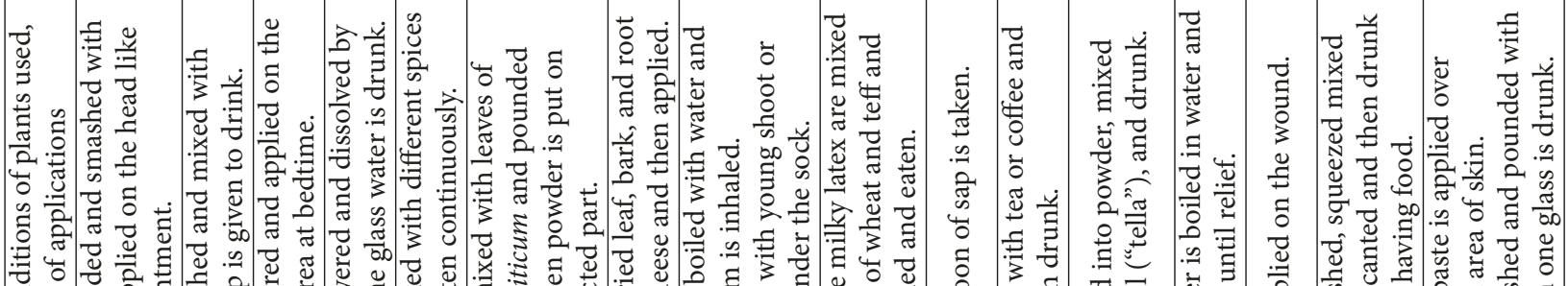

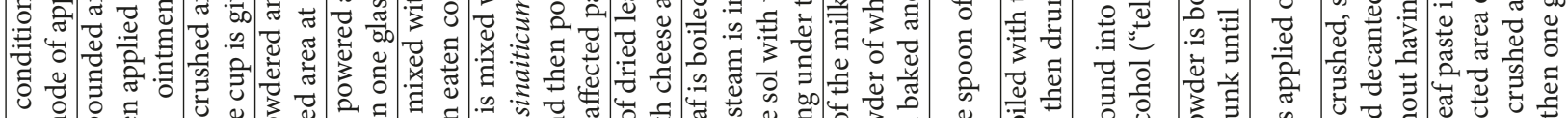

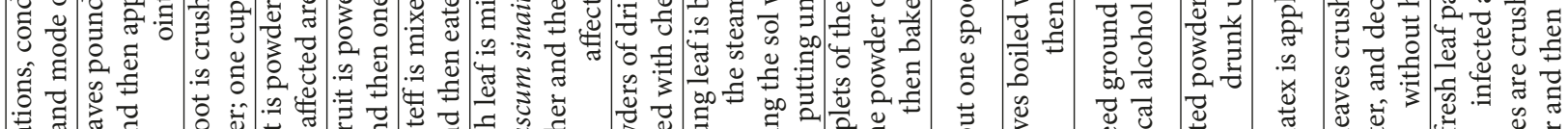

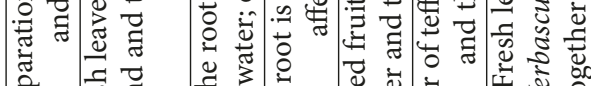

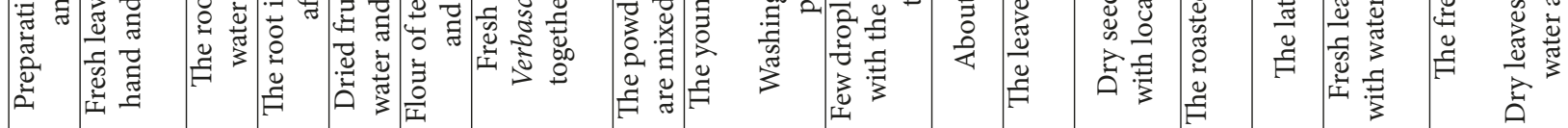

离

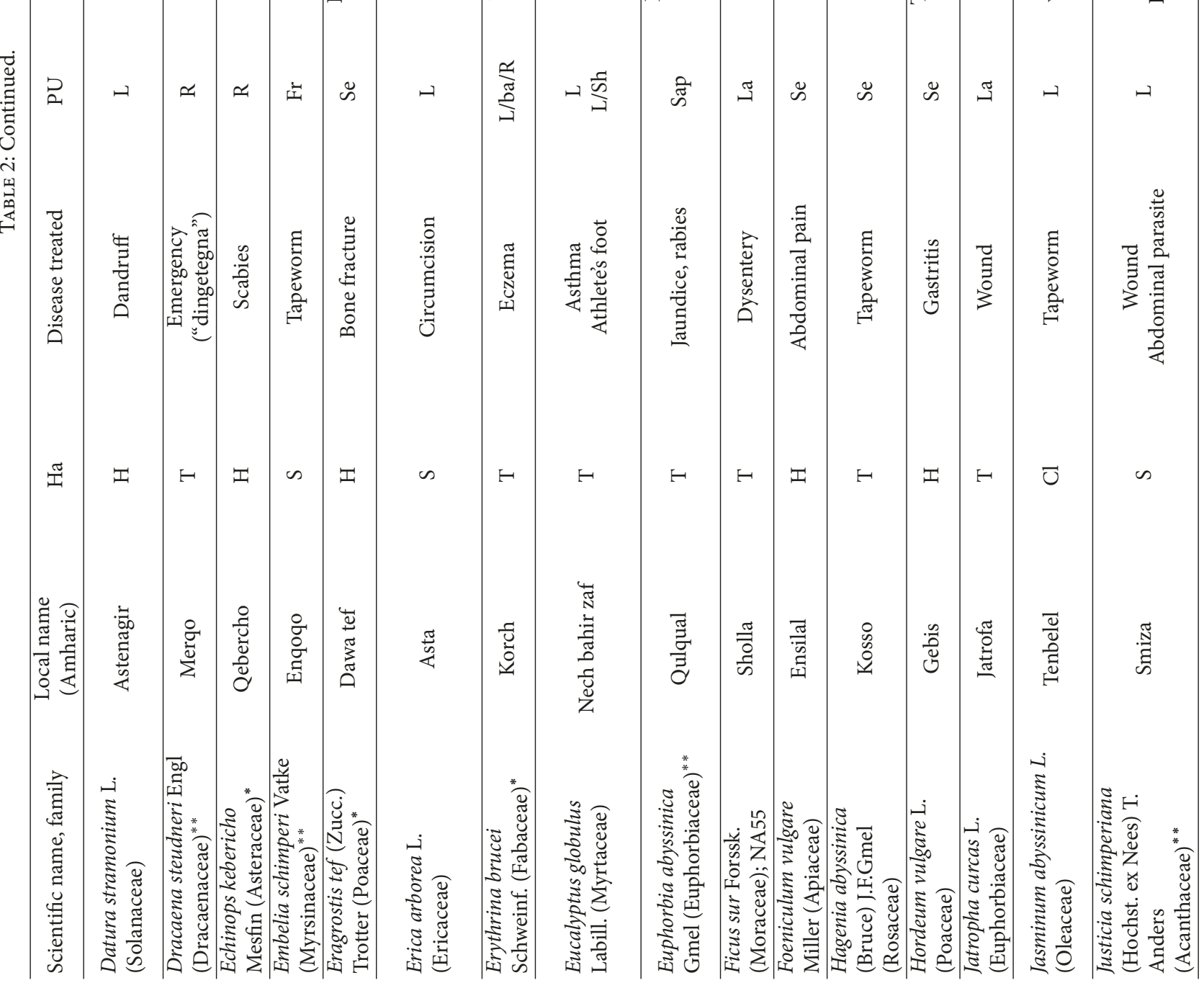




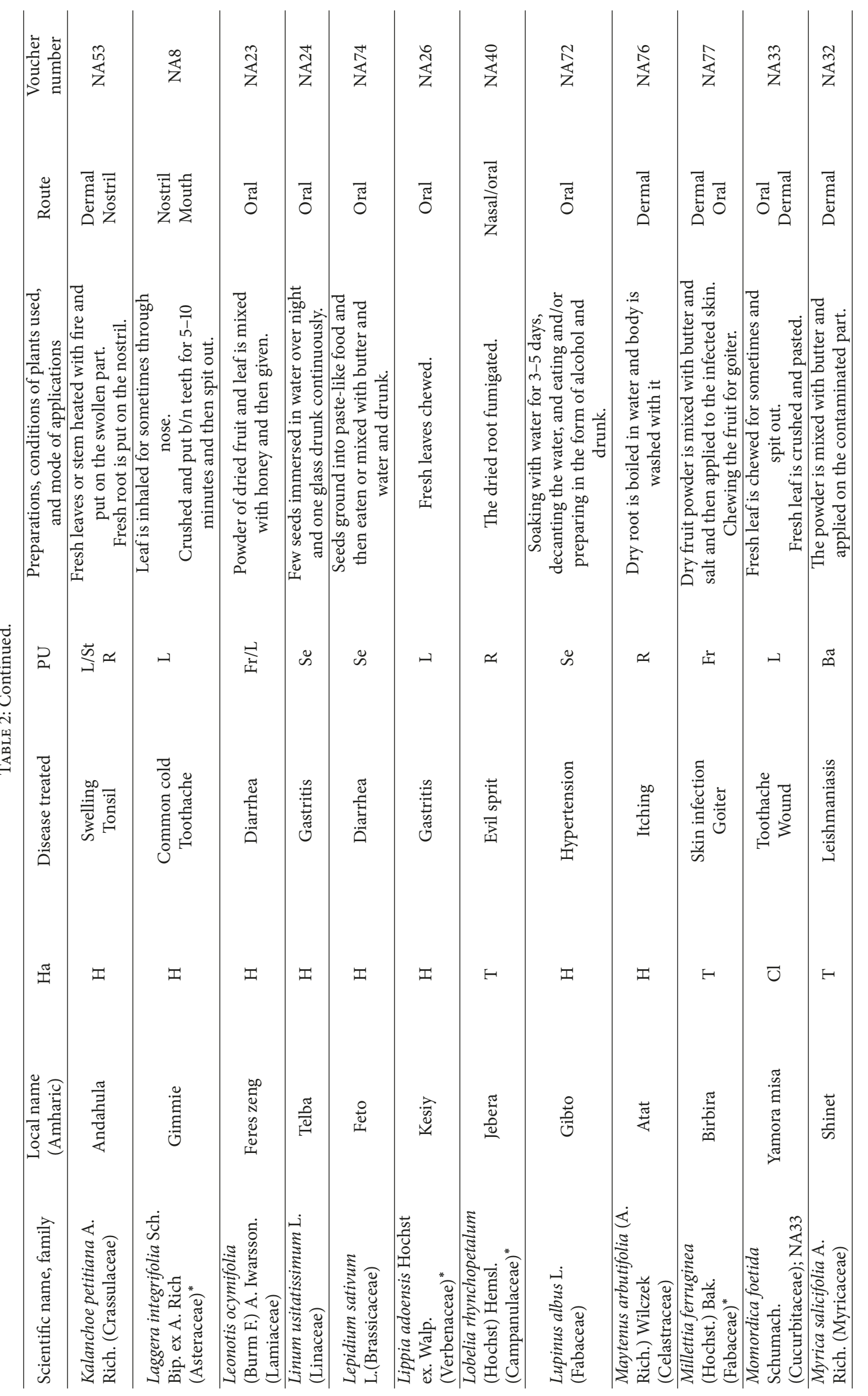




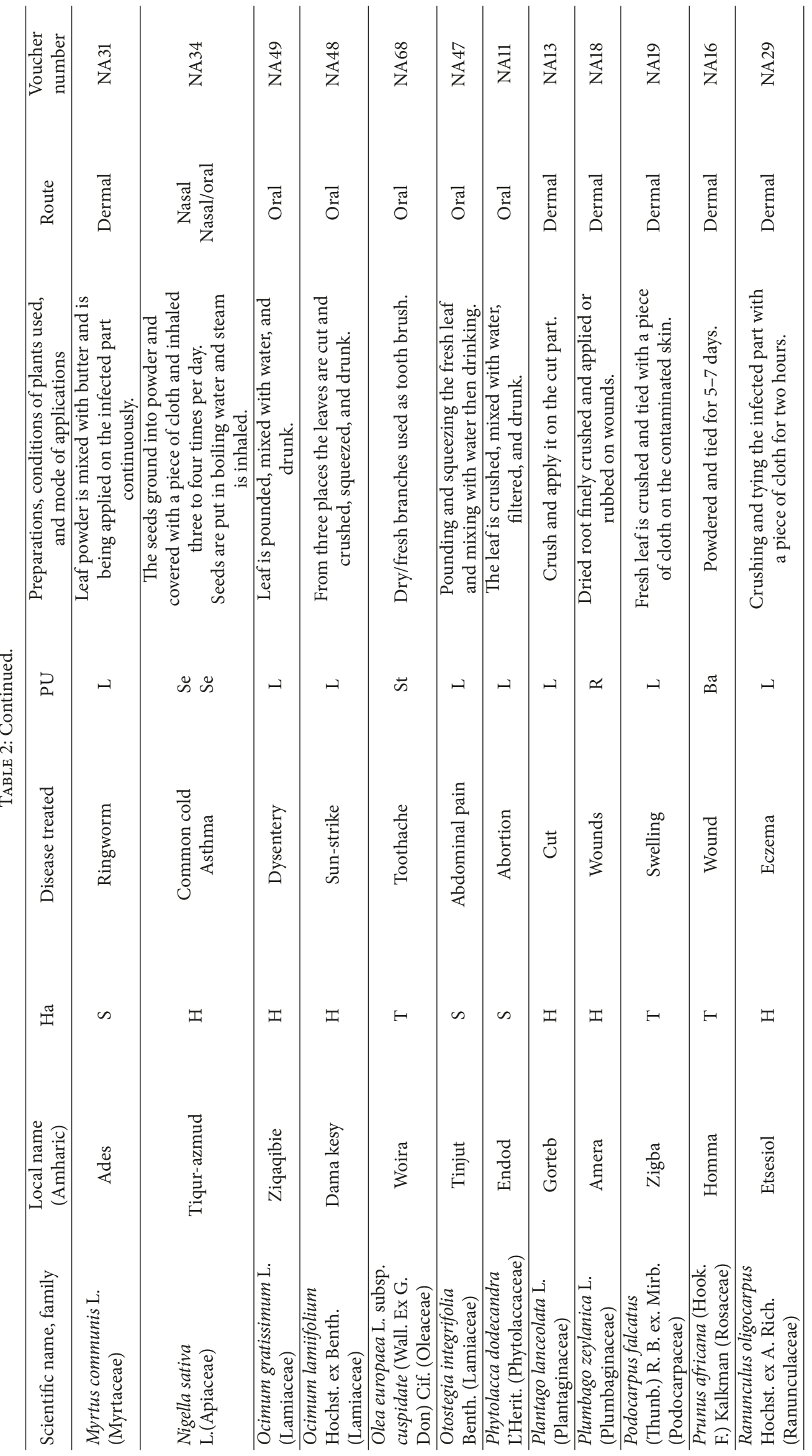




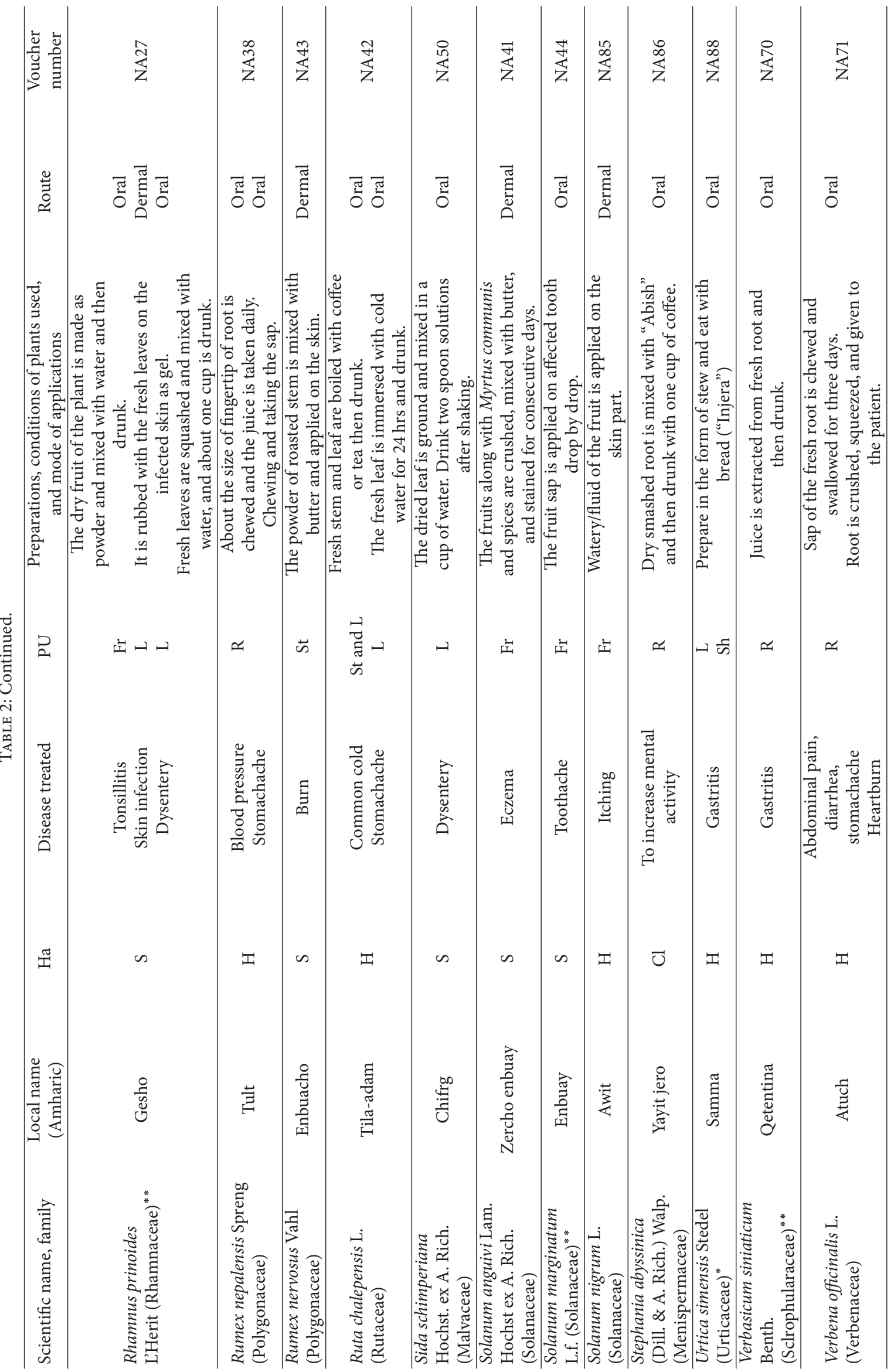




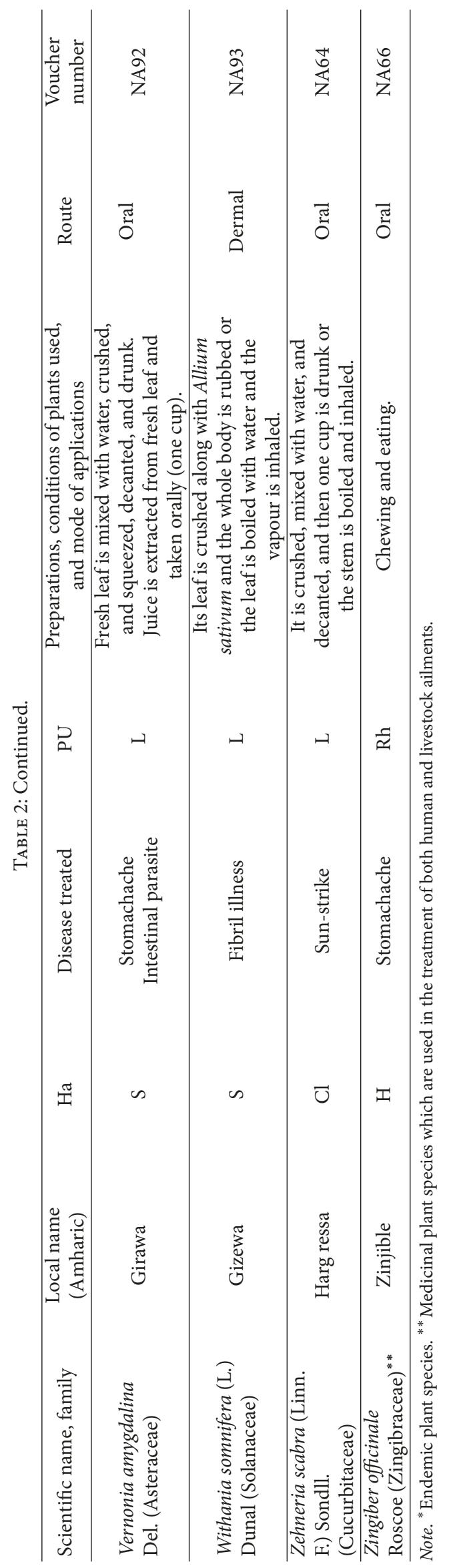




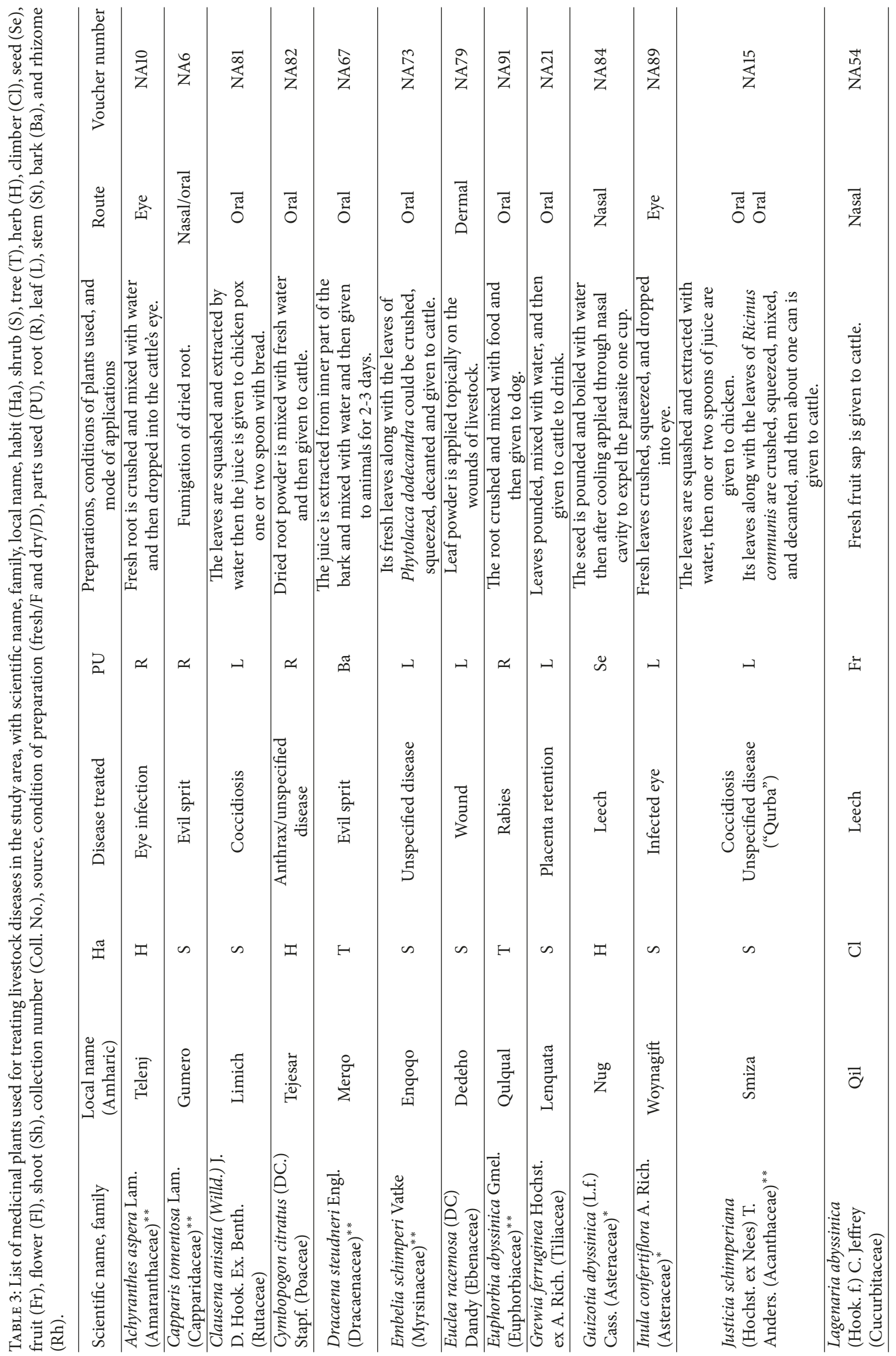




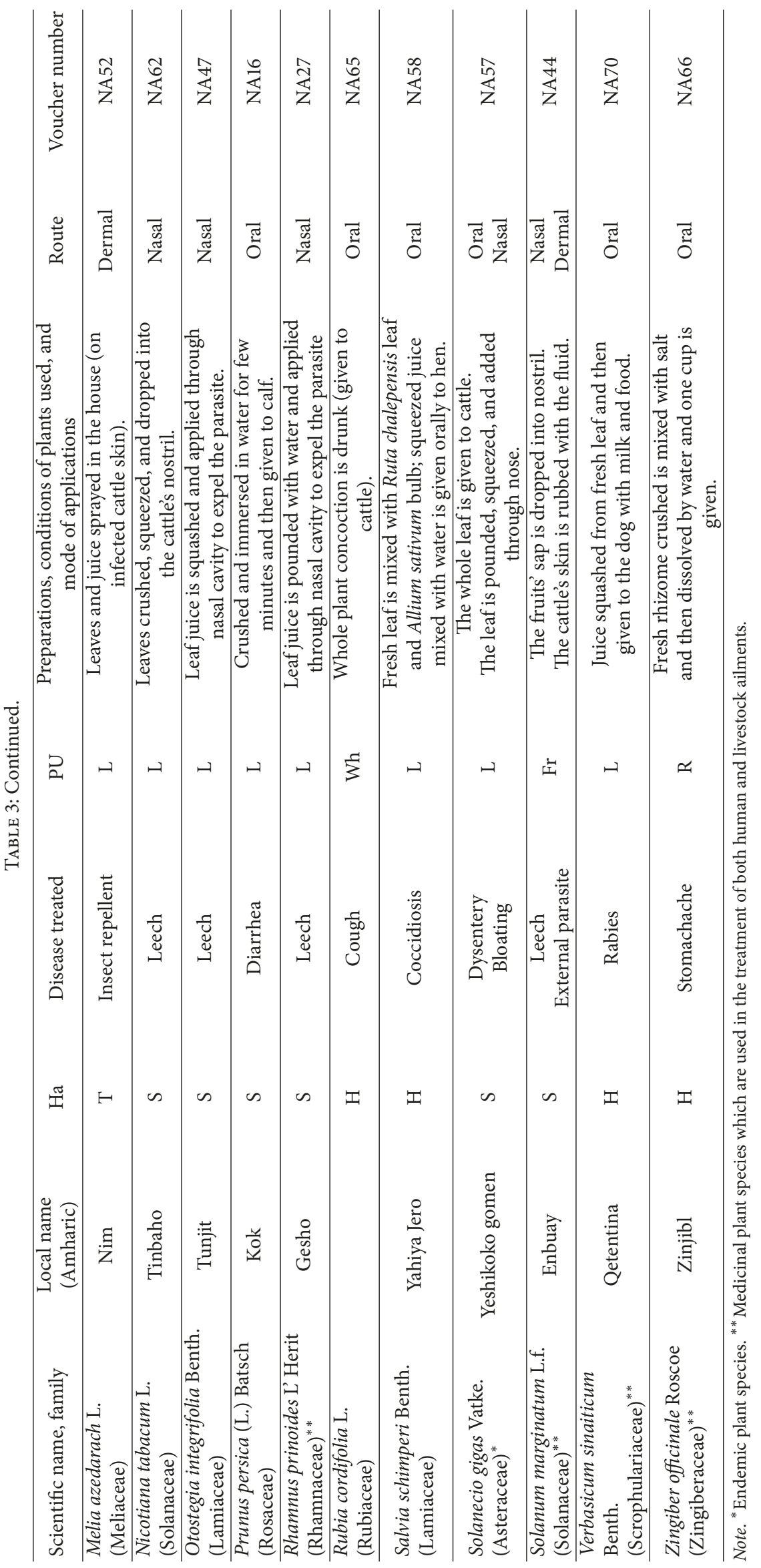




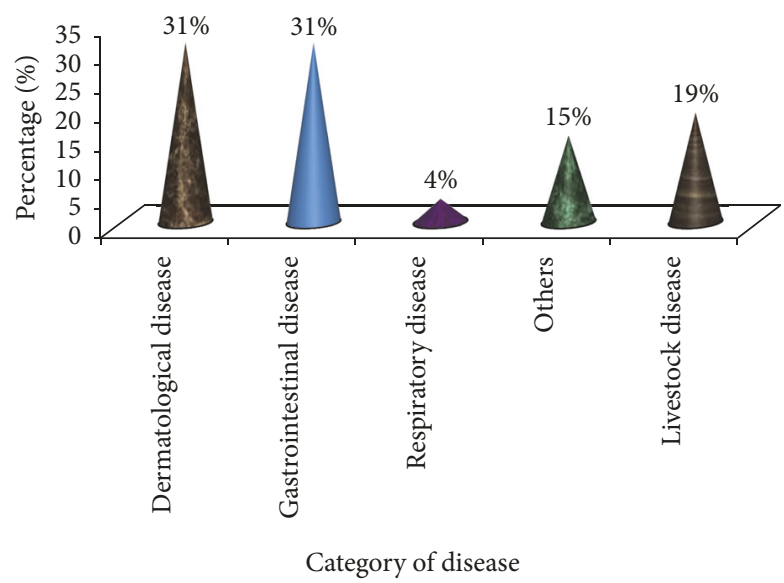

FIgURE 6: Categories of disease.

the dearth of the MPs. Fortunately, the plant parts which are mostly used for the preparation of the remedies in the study area were leaves and harvesting of leaves has less impact on the plant than harvesting of roots.

3.6. Disease Categories in the Study Area. Diseases can be categorized in different ways as dermatological, respiratory, gastrointestinal, and so on. Based on the information obtained in the study site, the most prevalent diseases are related to skin (dermatology) and gastrointestinal ones (31\%, each) followed by livestock (19\%) and other diseases (15\%) (Figure 6). The study showed that dermatological diseases such as wound, skin rush, itching, and eczema are prevalent and a number of MPs were found to be cited so as to treat these skin diseases. Similarly, gastrointestinal diseases like stomachache, gastritis, abdominal pain, intestinal parasite, dysentery, diarrhea, vomiting, hepatitis, and other related diseases were treated by many MPs. Respiratory and other diseases were also treated by various MPs (Figure 6; Tables 2 and 3 ).

The health problems could be as inverse as the MPs and associated ecological zones. For example, Tolasa [32] reported 49 human health problems, which have been treated by 85 different MPs. Awas and Demissew [36] and Gebeyehu et al. [31] identified skin disease as the most commonly reported health problems in Kafficho people, Menjarna Shenkora and Mecha districts, respectively. On one hand Belayneh et al. [37] and Lulekal et al. [27] reported gastrointestinal diseases as the major human health problems. On the other hand, Mesfin et al. [34] reported malaria as the most common human health problem of Wonago district.

3.7. Diversity of Medicinal Plants in terms of Families. In this study different families of MPs were recorded. Among them Asteraceae is the most dominant family that holds 9 (9.68\%) plant species followed by Solanaceae having 7 (7.53\%) species. Other taxa commonly used are Cucurbitaceae and Lamiaceae (each 5 spp.), Euphorbiaceae and Fabaceae (each 4 spp.), Brassicaceae, Poaceae, and Rosaceae (each 3). The remaining forty-two (42) families hold fifty plant species. Eight of them account for two species. The rest of the families signify one

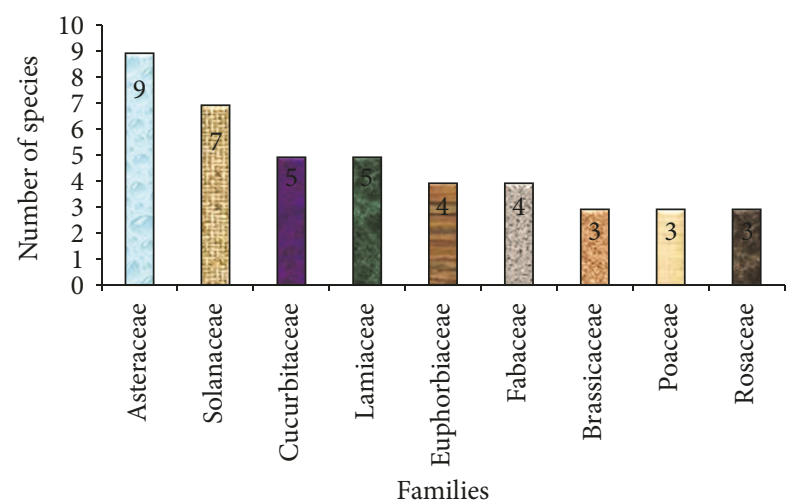

FIGURE 7: Families represented by highest number of medicinal plant species.

species (Figure 7; Tables 2 and 3). Our finding agreed with the finding of Gebeyehu et al. [31] in which Asteraceae is the dominant family followed by Solanaceae. Etana [38] also reported that Asteraceae is the dominant family followed by Fabaceae. This may be because the weedy nature of the family Asteraceae takes advantage of disturbance.

3.8. Habits of Medicinal Plants Which Treat Diseases. The finding shows that the most widely used MPs habits in the different Kebeles of the study areas were herbs, 42 (45\%), followed by shrubs 29 (31\%). Trees and climbers account for $15(16 \%)$ and $7(8 \%)$, respectively (see Figure 8). Herbs are largest in number; this may be because the plant species exhibit high level of abundance and it is easy to access them. The results of this finding agreed with the findings of other indigenous researchers including Berhan et al. [15], Giday et al. [12], and Teklehaymanot and Giday [39]. On the contrary, the findings of Hunde et al. [14], Giday and Ameni [9], Lulekal et al. [33], and Mesfin et al. [34] revealed that shrubs are the most commonly used habits in their respective different study sites of Ethiopia.

3.9. Traditional Methods of Preparation, Condition, and Route of Application. The popular method of preparation of traditional medicine is crushing and squeezing accounting for $54(45 \%)$ followed by powdering (powder form), 22 (18\%). It was also recorded that $13(11 \%)$ were prepared in juice form, $9(8 \%)$ in boiling form, $8(7 \%)$ in chewing form, and $4(3 \%)$ in the form of fumigation and immersion (each). Other methods such as paste form, raw form, and the like accounted for 6 (5\%) (Figure 9). Methods can be used for human and livestock problem except chewing which is used only for humans.

Based on the informants' information the most popular method of preparation of remedy in the study area was crushing. This finding is in line with the results of Yineger and Yewhalaw [16], Getaneh [30], and Amsalu et al. [28]. However, Mesfin et al. [34], in a similar study on people of Wonago Wereda, reported that powdering was dominant method of preparation of remedy.

The result in the conditions of plant part used indicated that most medicines (about 61\%) of traditional MPs 

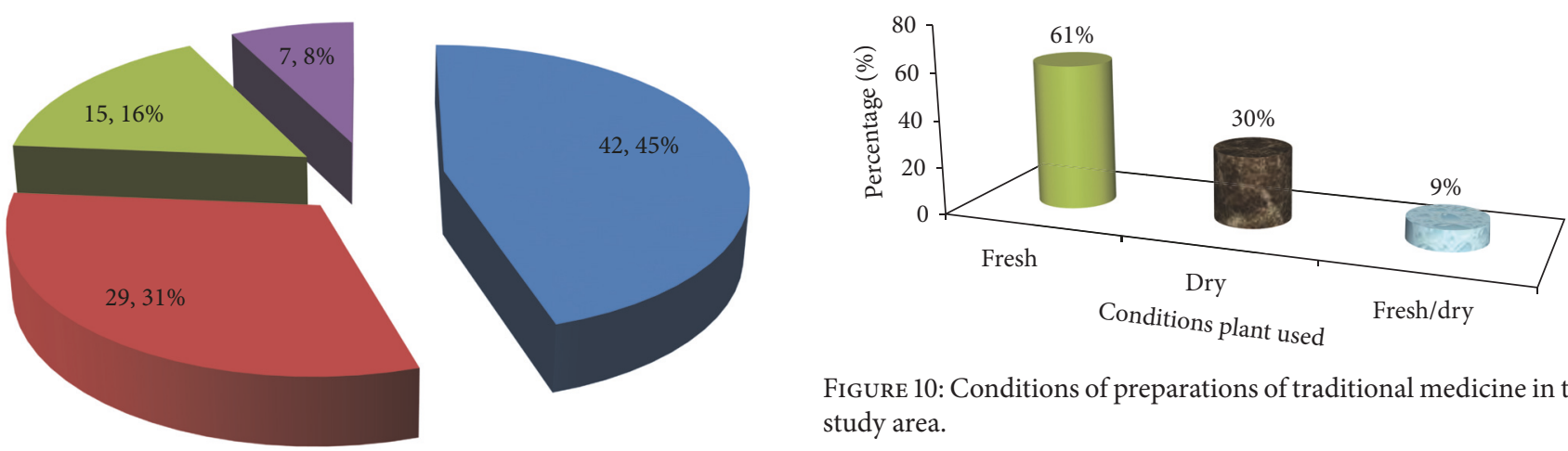

FIGURE 10: Conditions of preparations of traditional medicine in the study area.

$$
\begin{aligned}
& \text { Habit of MPs } \\
& \text { Herb } \\
& \text { Shrubs } \\
& \text { Trees } \\
& \text { Climbers }
\end{aligned}
$$

FIGURE 8: Habits of medicinal plants.

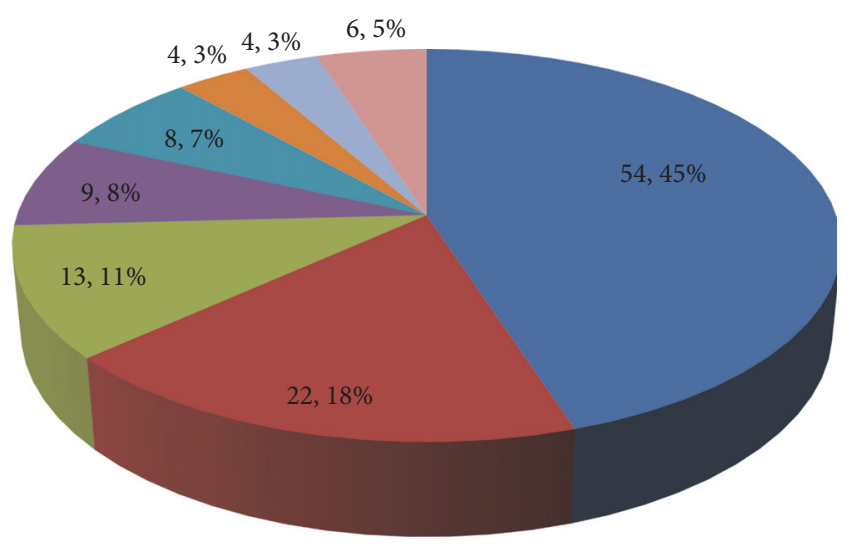

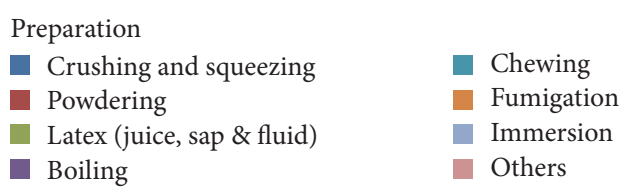

FIGURE 9: Ways of preparation of traditional medicine in the study area.

were prepared from fresh plant materials in the study site whereas $30 \%$ and $9 \%$ of medicinal plants were reported to be used dry and in both dry or fresh form, respectively (Figure 10). The most common use employs fresh (intact or pounded/crushed) leaves for external administration.

This finding is also consistent with the finding of $[23,26$, $28-30,32,34,36,40]$ that reported that the majority of the remedy preparations were in fresh form. In contrast with this, Tolasa [32] stated that $60 \%$ of the preparations are fresh or dried followed by fresh, $36.47 \%$, and dried, $14 \%$.

Respondents argued that they use fresh plant parts mostly because they believe that using fresh materials increases efficacy as compared to the dry ones. This is because of the fact that the ingredients may be lost or reduced when the

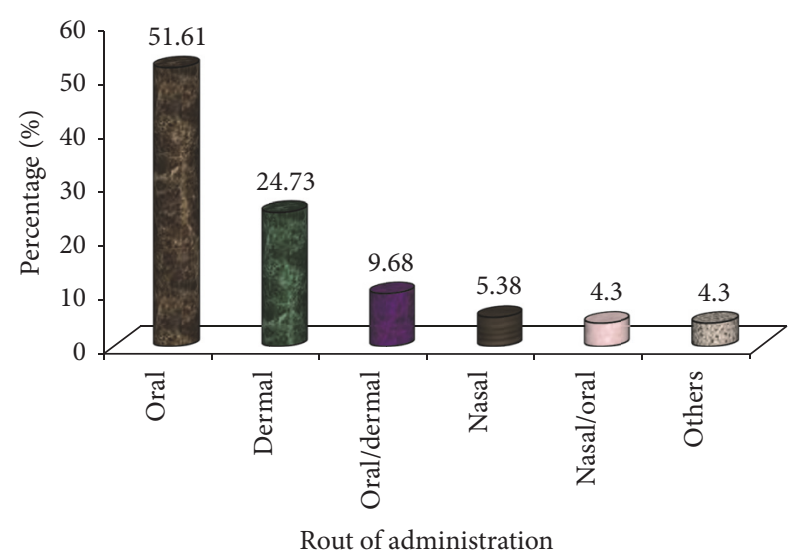

Figure 11: Route of administrations.

plants became dry. Nevertheless, this contributes much a lot to the threats of MPs given that local people have no practice of preserving dry form of traditional medicine.

On the other hand, the most common route of administration is internal particularly oral that accounted for $51.61 \%$ followed by dermal, $24.73 \%$. The oral/dermal, nasal, and nasal/oral ones and others are indicated in Figure 11. This result is being in agreement with the findings made by Megersa et al. [23] and Amsalu et al. [28], who reported that the leading route of application used by the given community in their respective study areas of remedies is taking orally.

3.9.1. Dosage. Dosages were estimated using lid spoons, pinches, or handfuls ("woket") (for powder preparations), cups ("sini" or "finjal"), "tassa" (can), and glasses (birchiko) (for liquid mixtures to be administered), numbers or in some cases handfuls (for leaf, seed, and fruits), and "atik" (for roots, stems, or barks). The measurements used to determine the dosages are not standardized and depend on the age, physical appearance of the patient, degree of the illness, diagnosis, and experience of individual herbalists/knowledgeable person. Children are given less than adults, such as one-fourth of a coffee cup whereas an adult is given up to one glass depending on the type of illness and treatment. Getahun [40] and Abebe [41] were also reporting independently lack of precision and standardization as drawback for the recognition of the traditional healthcare system. Giday and Ameni [9] also reported similar results. 
TABLE 4: Preference ranking of six medicinal plants against leech in livestock (cited by six respondents).

\begin{tabular}{|c|c|c|c|c|c|c|c|c|}
\hline \multirow{2}{*}{ Medicinal plants } & \multicolumn{6}{|c|}{ Respondents $\left(\mathrm{R}_{1}-\mathrm{R}_{6}\right)$} & \multirow{2}{*}{ Total } & \multirow{2}{*}{ Rank } \\
\hline & $\mathrm{R}_{1}$ & $\mathrm{R}_{2}$ & $\mathrm{R}_{3}$ & $\mathrm{R}_{4}$ & $\mathrm{R}_{5}$ & $\mathrm{R}_{6}$ & & \\
\hline Guizotia abyssinica & 3 & 2 & 2 & 2 & 2 & 1 & 12 & 6th \\
\hline Lagenaria abyssinica & 3 & 2 & 2 & 3 & 2 & 2 & 14 & 5 th \\
\hline Otostegia integrifolia & 1 & 4 & 3 & 3 & 3 & 2 & 16 & 4 th \\
\hline Rhamnus prinoides & 4 & 4 & 3 & 4 & 4 & 4 & 23 & 2nd \\
\hline Solanum marginatum & 4 & 4 & 3 & 4 & 4 & 4 & 23 & 3 rd \\
\hline Nicotiana tabacum & 4 & 4 & 3 & 4 & 5 & 5 & 25 & 1st \\
\hline
\end{tabular}

Note. Scores in the table indicate ranks given to medicinal plants based on their efficacy. Highest number (5) is given to the medicinal plant which informants thought to be most effective in treating leech and the lowest number (1) is given to the least effective plant.

TABLE 5: Paired comparison of five medicinal plants used to treat toothache.

\begin{tabular}{|c|c|c|c|c|c|c|c|c|c|}
\hline \multirow{2}{*}{ Medicinal plants } & \multicolumn{7}{|c|}{ Respondents $\left(\mathrm{R}_{1}-\mathrm{R}_{7}\right)$} & \multirow{2}{*}{ Total } & \multirow{2}{*}{ Rank } \\
\hline & $\mathrm{R}_{1}$ & $\mathrm{R}_{2}$ & $\mathrm{R}_{3}$ & $\mathrm{R}_{4}$ & $\mathrm{R}_{5}$ & $\mathrm{R}_{6}$ & $\mathrm{R}_{7}$ & & \\
\hline Acmella caulirhiza & 3 & 4 & 4 & 4 & 3 & 5 & 3 & 27 & $1 s t$ \\
\hline Laggera tomentosa & 3 & 4 & 3 & 3 & 3 & 3 & 4 & 23 & $2 \mathrm{nd}$ \\
\hline Olea europaea subsp. cuspidata & 2 & 3 & 3 & 3 & 3 & 2 & 3 & 19 & $3 \mathrm{rd}$ \\
\hline Solanum marginatum & 3 & 2 & 2 & 3 & 2 & 2 & 3 & 17 & 4 th \\
\hline Momordica foetida & 2 & 2 & 2 & 2 & 3 & 2 & 3 & 16 & 5 th \\
\hline
\end{tabular}

Note. A paired comparison of five highly cited MPs used to treat a highly cited human ailment (toothache).

\subsection{Ranking of Medicinal Plants}

3.10.1. Preference Ranking. If a number of species are prescribed for the same ailment, people would tend to show preference of one over the other. Thus, preference ranking of six MPs which were reported against leach (livestock disease) was conducted after selecting six key informants. The informants were asked to compare the given MPs based on their efficacy and to give the highest number (5) for the medicinal plant which they thought most effective against leech and the lowest number (1) for the least effective plant in treating the disease. The results showed that Nicotiana tabacum was the most preferred followed by Rhamnus prinoides and Solanum marginatum (see Table 4).

Result of the preference ranking exercise also indicated that Nicotiana tabacum is the most preferred ethnoveterinary MPs used to treat leech, the most commonly reported disease in the area. This may be attributed to the presence of bioactive compounds against leech in this plant species. Hence, the species should be further investigated in the laboratory for further activities and even against different ailments.

3.10.2. Paired Comparison. In this study, seven key informants made the pairwise comparisons of five MPs and the values were summarized as follows. It was found that Acmella caulirhiza species stood first followed by Laggera tomentosa for the treatment of toothache. Olea europaea subsp. cuspidata, Solanum marginatum, and Momordica foetida were placed 3rd, 4th, and 5th, respectively (Table 5). This rank is because of the effectiveness of the plant in the point of view of the indigenous people of Gozamin Wereda.

3.10.3. Direct Matrix Ranking. Many MPs were found to be used for different purposes in addition to their medicinal values. The major uses include firewood, furniture, forage, charcoal, and eating. For ranking seven key informants were asked to give value, 5 to the most used plant for that particular purpose and 0 to the least used one. In view of that, Cordia africana was found to be the most multipurpose plant scoring 93, followed by Carissa spinarum scoring 87 , and the least one was Croton macrostachyus having score of 72 (Table 6). The highest direct matrix ranking on the topic of Cordia africana was also reported in Gebeyehu et al. [31]. This confirms that as the value is getting high the plants have multiple uses in the context of the local community.

Direct matrix of randomly selected MPs with different uses including medicinal value on given use criteria revealed that MPs broadly collected for different purposes such as charcoal, construction, fencing, firewood, forage, furniture, and the like were also indicated $[28,38]$.

3.11. Jaccard's Coefficient of Similarity (JCS). Jaccard's Coefficient of Similarity (JCS) revealed that the study area has the highest similarity with 45 common species (34.66\%) to the study conducted around Wonago Wereda, followed by 40 common species (28\%) with Debre Libanos Wereda, followed by 39 common species (21.91) with Chelya Wereda, followed by 30 common species (17.65) having similarity to Gimbi Wereda, followed by 23 common species (17.16\%) having similarity to Zegie. The least similarity was linked with the study conducted on Bale Mountain National Park (Table 7).

3.12. Fidelity Level. Fidelity levels were calculated for Plumbago zeylanica, Prunus africanus, Solanum anguivi Lam., and Withania somnifera having highest scores (100\%) which treat diseases like wounds, eczema, and fibril illness (Table 8). On the other hand, Rhamnus prinoides which treats tonsillitis, 
TABLE 6: Direct matrix ranking for the multipurpose of six medicinal plants [average score of 7 key informants (5 to the most used plant for that particular purpose and 0 to the least used one)].

\begin{tabular}{|c|c|c|c|c|c|c|c|c|}
\hline \multirow{2}{*}{ Medicinal plants } & \multicolumn{6}{|c|}{ Use categories } & \multirow{2}{*}{ Total } & \multirow{2}{*}{ Rank } \\
\hline & Medicine & Firewood & Furniture & Forage & Soil con. & Edible & & \\
\hline Cordia africana & 24 & 20 & 24 & 5 & 10 & 10 & 93 & $1 s t$ \\
\hline Carissa spinarum & 27 & 17 & 5 & 10 & 12 & 16 & 87 & 2nd \\
\hline Prunus africanus & 20 & 21 & 20 & 5 & 8 & 8 & 82 & $3 r d$ \\
\hline Olea europaea subsp. cuspidate & 20 & 22 & 14 & 5 & 9 & 5 & 75 & 4th \\
\hline Vernonia amygdalina & 30 & 20 & 15 & 0 & 8 & 0 & 73 & 5 th \\
\hline Croton macrostachyus & 29 & 19 & 18 & 0 & 6 & 0 & 72 & 6th \\
\hline
\end{tabular}

TABLE 7: Jaccard's Coefficient of Similarity index with six other areas with respect to plants species composition.

\begin{tabular}{|c|c|c|c|c|c|}
\hline Sample of study areas & $\mathrm{A}$ & $\mathrm{B}$ & $\mathrm{C}$ & JCS\% & References \\
\hline Gozamin Wereda & 93 & - & - & - & Present \\
\hline Bale Mountain National Park & 101 & 86 & 15 & 7.42 & Yineger et al. 2008 \\
\hline Chelya District & 89 & 50 & 39 & 21.91 & Amenu, 2007 \\
\hline Debre Libanos District & 90 & 50 & 40 & 22.22 & Getaneh, 2009 \\
\hline Gimbi District & 85 & 55 & 30 & 17.65 & Tolasa, 2007 \\
\hline Wonago District & 65 & 20 & 45 & 34.66 & Mesfin et al. 2009 \\
\hline Zegie Peninsula & 67 & 44 & 23 & 17.16 & Teklehaymanot and Giday, 2007 \\
\hline
\end{tabular}

skin infection, and dysentery has the least score (50\%) (Table 8). Plants that are known as remedies of a single ailment have $100 \%$ fidelity level as compared to those that are used as remedies for more than one type of aliment. Most of the plants with high FL values have pharmacological effects that have been proven scientifically. On the other hand, the lowest one indicated less preferred species for treating specific ailments. In contrast, these plants have been widely used against several diseases. Plants with highest fidelity level values could also be targeted for further photochemical investigation to prove the bioactive components that are responsible for their high healing potential [42].

3.13. Nutraceuticals. Of the total MPs collected, twenty $(21.51 \%)$ of them are used as a source of both medicine and food (nutraceuticals). The ethnobotanical information revealed that many food crops have medicinal effects (Table 9). The following plants like Allium sativum, Brassica carinata, Brassica nigra, and so on are directly used as a source of medicine and food in the study area of the given community. From this one can easily understand that the local people have IK and age-old experience in the use of plants as a source of medicine and nutrition. Similar findings were reported by Reta [43]. Most TMPs are safe, some are nutraceuticals, some are functional foods (wild fruits, vegetables, and other crops), and hence they are preferred.

3.14. Threatened and Endemic Medicinal Plants in the Study Area. In the study area, ethnobotanical information disclosed that MPs like Hagenia abyssinica, Olea europaea subsp. cuspidata, Podocarpus falcatus, Juniperus procera, Euphorbia abyssinica, Myrica salicifolia, Cucumis ficifolius, Withania somnifera, Cordia africana, Brucea antidysenterica, Ficus sur, and Millettia ferruginea are highly threatened. Medicinal plants documented as endemic from Ethiopia to the study site were Brassica carinata, Eragrostis tef, Cynoglossum coeruleum, Echinops kebericho, Erythrina brucei, Guizotia abyssinica, Inula confertiflora, Lippia adoensis, Lobelia rhynchopetalum, Millettia ferruginea, Solanecio gigas, and Urtica simensis which accounted for 13\% (12 plant species) of the total collected MPs. Out of these, Cynoglossum coeruleum, Inula confertiflora, Laggera tomentosa, and Lobelia rhynchopetalum are nearly threatened while Lippia adoensis, Solanecio gigas, and Urtica simensis were under least concern (LN) [44]. This list could be used for collection of the rare plants of Ethiopia and contribute to national plant conservation target.

\subsection{Threats and Conservation of Medicinal Plants in the Study Area}

3.15.1. Threats of Medicinal Plants. As elsewhere in Ethiopia, plant resources are vital for the livelihood of the Amhara people of Gozamin community. In the study sites, the resources are eroded from time to time because of the increment of population. Associated with this, the demand of agriculture (raring of livestock and cultivation) is high and therefore overgrazing and clearance of vegetation/forests are high. There is evidence of remnant plants at the spot in the grazing lands and farmlands of representative Kebeles in the Wereda where the data were collected. This indicates that overgrazing and deforestation were the main cause of the devastation of plants in the study area. Priority ranking factors (Table 10) also indicated that overgrazing contributed the major factor $(26.12 \%)$ to the threat of MPs followed by charcoal and firewood (23.42\%) and deforestation (23.42\%) (for agricultural expansion, furniture, and building). Drought and mining are other destructive factors, which account for $14.41 \%$ and $12.61 \%$ of the total scores, respectively. 
TABLE 8: Fidelity level of traditional medicinal plants cited by informants against the corresponding human ailment.

\begin{tabular}{lcccc}
\hline Plant species & Diseases treated & $N P$ & $N$ & FL values (\%) \\
\hline Plumbago zeylanica & Wounds & 7 & 7 & 100 \\
Prunus africanus & Wounds & 8 & 10 & 100 \\
Solanum anguivi Lam. & Eczema & 10 & 5 & 100 \\
Withania somnifera & Fibril illness & 5 & 15 & 100 \\
Verbena officinalis & Stomachache and intestinal parasite & 18 & 24 & 70 \\
Rumex nepalensis & Blood pressure and stomachache & 15 & 20 & 75 \\
Brucea antidysenterica & Diarrhea, wound and leishmaniasis & 25 & 35 & 71.42 \\
Laggera tomentosa & Common cold and toothache & 25 & 45 & 55.56 \\
Carica papaya & Gastritis, malaria, and diarrhea & 20 & 40 & 50 \\
Rhamnus prinoides & Tonsillitis, skin infection, and dysentery & & \\
\hline
\end{tabular}

$\mathrm{FL}=$ fidelity level; $N P=$ number of informants who independently cited the importance of a species for treating a particular disease; $N=$ total number of informants who reported the plant for any given disease.

TABLE 9: Lists of nutraceutical (used as both food and medicine) plants.

\begin{tabular}{|c|c|c|c|c|}
\hline Botanical names & Family & $\begin{array}{l}\text { Local names } \\
\text { (Amharic) }\end{array}$ & Uses as food & Disease treated \\
\hline Allium sativum & Alliaceae & Nech shinkurt & Bulb and leaf as food & Cough, evil eye, asthma \\
\hline Brassica carinata & Brassicaceae & Gomen & Leaf/seed as food; oil & Skin rush \\
\hline Brassica nigra & Brassicaceae & Sinafich & Used as spice & Abdominal pain \\
\hline Capsicum annum & Solanaceae & Qaria & Fruit used as spice & Vomiting, dysentery \\
\hline Carissa spinarum & Apocynaceae & Agam & Edible fruit & Evil eye \\
\hline Coffea arabica & Rubiaceae & Bunna & As stimulant & Wound \\
\hline Eragrostis tef & Poaceae & Teff & Human food & Bone fracture \\
\hline Ficus sur & Moraceae & Shoal & Edible fruit & Dysentery \\
\hline Foeniculum vulgare & Brassicaceae & Ensilal & Used as spice & Abdominal pain \\
\hline Guizotia abyssinica & Asteraceae & Nug & Sources of oil and fodder & Leech \\
\hline Hordeum vulgare & Poaceae & Gebis & Food and fodder & Gastritis \\
\hline $\begin{array}{l}\text { Linum } \\
\text { usitatissimum }\end{array}$ & Linaceae & Telba & Oil crop and fodder & Gastritis \\
\hline Lepidium sativum & Brassicaceae & Feto & Used as spices/food & Diarrhea \\
\hline Lupinus albus & Fabaceae & Gibito & Seed used as food & Hypertension \\
\hline Nigella sativa & Apiaceae & Tiqur-azmud & Used as spice & Common cold, asthma \\
\hline Prunus persica & Rosaceae & Kok & Edible fruit & Diarrhea \\
\hline Rhamnus prinoides & Rhamnaceae & Gesho & Stimulant/spices & $\begin{array}{l}\text { Leech, tonsils, skin } \\
\text { infection }\end{array}$ \\
\hline Ruta chalepensis & Rutaceae & Tila-adam & Seed/leaf as spices & Stomachache \\
\hline Urtica simensis & Urticaceae & Samma & Edible leaf & Gastritis \\
\hline Zingiber officinale & Zingiberaceae & Zinjibl & Used as spice & Stomachache \\
\hline
\end{tabular}

TABLE 10: Ranking of threats on medicinal plants cited by 7 respondents (values 1-5: $1=$ the least destructive and $5=$ the most destructive) (a single respondent mentioned two or more threats).

\begin{tabular}{|c|c|c|c|c|c|c|c|c|c|c|}
\hline \multirow{2}{*}{ Threats } & \multicolumn{7}{|c|}{ Respondents $\left(\mathrm{R}_{1}-\mathrm{R}_{7}\right)$} & \multirow{2}{*}{ Total } & \multirow{2}{*}{$\%$} & \multirow{2}{*}{ Rank } \\
\hline & $\mathrm{R}_{1}$ & $\mathrm{R}_{2}$ & $\mathrm{R}_{3}$ & $\mathrm{R}_{4}$ & $\mathrm{R}_{5}$ & $\mathrm{R}_{6}$ & $\mathrm{R}_{7}$ & & & \\
\hline Overgrazing & 5 & 4 & 4 & 5 & 4 & 4 & 3 & 29 & 26.12 & 1st \\
\hline Charcoal and firewood & 4 & 4 & 5 & 4 & 3 & 3 & 3 & 26 & 23.42 & 2nd \\
\hline Deforestation & 4 & 4 & 4 & 4 & 3 & 4 & 3 & 26 & 23.42 & $2 \mathrm{nd}$ \\
\hline Drought & 3 & 3 & 3 & 2 & 1 & 2 & 2 & 16 & 14.41 & 4 th \\
\hline Mining & 3 & 2 & 3 & 2 & 1 & 1 & 2 & 14 & 12.61 & 5 th \\
\hline
\end{tabular}


Almost all of the informants are familiar with one and more than one threat for the scarcity of medicinal plants in the study area. Deforestation for firewood, charcoal, construction, agriculture, and mining is common practice in the study areas. The previous vegetation site has been changed drastically and the most useful plant species are at risk and they are on the way to be vanished. Similarly, Balemi et al. [13] reported that overgrazing was principal threat to MPs in Fentalle area. On the other hand, the findings of Leulekal et al. [33], Megersa et al. [23], and Chekole et al. [25] indicated that intense deforestation became the major threat on MPs in their respective study sites. Berhanu et al. [15] and Kefalew et al. [24] also reported that agricultural expansion was the major factor contributing to the local decline of medicinal plants.

3.16. Conservation and Management Practices. In Gozamin Wereda, irregular remnants of aged dry Afromontane evergreen forests that contain many MPs can be found mainly around the Ethiopian Orthodox Tewahedo Churches. Hence, someone sees a patch of indigenous old-aged trees in the study area; he/she can be sure that there is an Orthodox Church in the middle. Patches of forests are visible from a great distance. Similar findings were reported in Chekole et al. [25]. This shows that culture, belief, and religion contribute much a lot to the conservation of MPs.

Some traditional practitioners in the study area have brought the different curative plans from different corners and started to conserve these MPs by cultivating at homegardens. On the topic of this, Asfaw [11] in his findings reported that the home-garden is a strategic and ideal farming system for conservation, production, and enhancement of MPs and valuable IK. The same information was also documented by Etana [38].

Likewise, few management practices are carried out in the home-gardens of Gozamin's indigenous people. One of the practices is to the make an effort for maintaining diverse plant species in the garden as much as possible. Diversity is achieved through planting and protecting annual and perennial herbs and woody perennials in combinations. Management practices like intercropping and crop rotation were observed among very few farmers of the study area. In doing so, herbal remedies continued to exist because of the existence of other plant species. As a result, indigenous people can be excellent conservators of plant diversity. However, according to the informants, in most cases attempts regarding conservation were weak. Similarly, Lulekal et al. [27] reported that although traditional practitioners and local communities in their study sites mainly depend on the natural environment for collecting MPs, the effort to conserve and sustainably utilize resources was frail.

\section{Conclusions}

Through the ethnobotanical survey conducted from January 5, 2014, to February 15, 2015, a total of 93 MPs under 51 families and 87 genera were recorded and documented from 12 sample Kebeles of the local people for the treatment of different human and livestock ailments. The majority of the reported medicinal plant species were harvested from natural habitats. Furthermore, about $13 \%$ of medicinal plants of the study area were found endemic to Ethiopia. Both human and livestock health problems were most frequently treated by fresh plant material. Herbs were reported as the most dominant growth forms in the preparation of traditional remedies followed by shrubs, trees, and climbers. Leaves followed by roots were the dominant plant parts used for preparation of most remedies.

This study showed that traditional herbal medicine is playing a significant role in meeting the primary healthcare needs of Gozamin community. Acceptance of traditional herbal medicine and limited access to modern healthcare services could be considered as the main factors for the continuation of the practice. Some plant species were also reported to have uses other than their medicinal values. However, the efforts on the use and conservation of medicinal plants and associated indigenous knowledge were observed to be poor. Hence, awareness about the need for in situ and ex situ conservation should be created among the local communities and urgent measures must be given to threatened plant species.

\section{Conflicts of Interest}

The authors declare that they have no conflicts of interest.

\section{Authors' Contributions}

All authors had significant intellectual contribution to the design of the study, data collection and analysis, and writeup of the manuscript. Authors conducted the fieldwork, identified the plants, analyzed the data, wrote the draft manuscript, and actively followed it up through revisions up to submission and after. Nigussie Amsalu designed the study, collected data, and confirmed the identification of the plants and data analysis; Yilkal Bezie was responsible for data collection, data analysis, and write-up and checked the final version; Mulugeta Fentahun was responsible for data collection, reviewed and edited the draft manuscript, provided comments and suggestions, and checked its final version. Addisu Alemayehu and Gashaw Amsalu were also responsible for data collection and reviewing the paper and hence all authors read and approved the final manuscript and agreed to its submission.

\section{Acknowledgments}

The authors gratefully acknowledge the financial support received from Research and Directorate Office of Debre Markos University in implementing this research. They are indebted to the inhabitants of Gozamin Wereda, especially herbal healers who undeservedly shared with them their knowledge on MPs along with their wonderful hospitality and kind response to their inquiries on information in the study areas during field activities. Finally, they would like to extend their gratitude to Wereda Agricultural and Rural Development Office for providing various secondary basic data in support of their study. 


\section{References}

[1] World Conservation Monitoring Center (WCMC), Conservation Biodiversity Data Sourcebook, World Conservation Monitoring Center, Cambridge, UK, 1994.

[2] Ethiopian Biodiversity Institute (EBI), Ethiopia's Fifth National Report to the Convention on Biological Diversity (CBD), 2014.

[3] Ethiopian Mapping Authority (EMA), Addis Ababa, Ethiopia, 1988.

[4] D. Abebe and A. Ayehu, Medicinal Plants and Eenigmatic Health Practices of Northern Ethiopia, B.S.P.E, Addis Ababa, 1993.

[5] Plant Genetic Resources Center (PGRC), in Proceedings of the Ethiopia, Country Report to the FAO International Technical Conference on Plant Genetic Resources, Addis Ababa, Ethiopia, 1995.

[6] Ethiopia: Second Country Report on the State of PGRFA to FAO, Institute of Biodiversity Conservation (IBC), Addis Ababa, Ethiopia, 2008.

[7] Z. Asfaw and T. Wondimu, Introduction to Ethnobiology, Department of Biology, Addis Ababa University, Addis Ababa, Ethiopia, 2007.

[8] World Health Organization (WHO), Traditional Medicine Strategy 2002-2005, World Health Organization (WHO), Geneva, Swizerland, 2002.

[9] M. Giday and G. Ameni, "An ethnobotanical survey on plants of veterinary. importance in two weredas of Southern Tigray, Northern Ethiopia," SINET: Ethiopian Journal of Science, vol. 26, no. 2, pp. 123-136, 2005.

[10] C. M. Cotton, Ethnobotany, Principles and Applications, John Wiley and Sons Ltd., Chichister, England, 1996.

[11] Z. Asfaw, "The role of home gardens in production and conservation of medicinal plants," in Conservation and Sustainable Use of Medicinal Plants in Ethiopia, M. Zewdu and A. Demissie, Eds., vol. 7, pp. 76-91, 2001, Proceedings of the National Workshop on Biodiversity conservation and Sustainable Use of Medicinal Plants in Ethiopia.

[12] M. Giday, Z. Asfaw, T. Elmqvist, and Z. Woldu, "An ethnobotanical study of medicinal plants used by the Zay people in Ethiopia," Journal of Ethnopharmacology, vol. 85, no. 1, pp. 4352, 2003.

[13] K. Balemie, E. Kelbessa, and Z. Asfaw, "Indigenous medicinal plants utilization, management and threats in Fentale area eastern Shewa," Ethiopia. Journal of Science, vol. 3, no. 1, pp. 3758, 2004.

[14] D. Hunde, Z. Asfaw, and E. Kelbessa, "Use of traditional medicinal plants by people of 'Boosat' Sub district, central eastern Ethiopia," Ethiopian Journal of Health Sciences, vol. 16, no. 2, pp. 141-155, 2006.

[15] A. Berhan, Z. Asfaw, and E. Kelbessa, "Ethnobotany of plants used as insecticides, repellents and antimalarial agents in Jabitehnan district, West Gojjam," SINET: Ethiopian Journal of Science, vol. 29, no. 1, 2006.

[16] H. Yineger and D. Yewhalaw, "Traditional medicinal plant knowledge and use by local healers in Sekoru District, Jimma Zone, Southwestern Ethiopia," Journal of Ethnobiology and Ethnomedicine, vol. 3, article 24, 2007.

[17] Gozamin Wereda Agricultural Office (GWAO), Debre Markos, Ethiopia, 2014.

[18] I. Friis, S. Demissew, and P. van Bruegel, "Atlas of the potential vegetation of Ethiopia," The Royal Danish Academy of Science and Letters, Biologiske Skrifter, vol. 58, 2010.
[19] EWNHS, Biodiversity of Hotspot of Ethiopia-Ethiopian Wild life and natural Conservations: A Glimpse at Biodiversity of Ethiopa, 2011.

[20] G. J. Martin, Ethnobotany: A method Manual. A "People and Plants" Conservation Manual, Champman and Hall, London, UK, 1995.

[21] M. Kent and P. Coker, Vegetation Description and Analysis: A Practical Approach, Belhaven press, London, UK, 1992.

[22] J. Friedman, Z. Yaniv, A. Dafni, and D. Palewitch, "A preliminary classification of the healing potential of medicinal plants, based on a rational analysis of an ethnopharmacological field survey among Bedouins in the Negev Desert, Israel," Journal of Ethnopharmacology, vol. 16, no. 2-3, pp. 275-287, 1986.

[23] M. Megersa, Z. Asfaw, E. Kelbessa, A. Beyene, and B. Woldeab, "An ethnobotanical study of medicinal plants in Wayu Tuka District, East Welega Zone of Oromia Regional State, West Ethiopia," Journal of Ethnobiology and Ethnomedicine, vol. 9, article 68, 2013.

[24] A. Kefalew, Z. Asfaw, and E. Kelbessa, "Ethnobotany of medicinal plants in Ada'a District, East Shewa Zone of Oromia Regional State, Ethiopia," Journal of Ethnobiology and Ethnomedicine, vol. 11, article 25, 2015.

[25] G. Chekole, Z. Asfaw, and E. Kelbessa, "Ethnobotanical study of medicinal plants in the environs of Tara-gedam and Amba remnant forests of Libo Kemkem District, northwest Ethiopia," Journal of Ethnobiology and Ethnomedicine, vol. 11, p. 4, 2015.

[26] H. Yineger, E. Kelbessa, T. Bekele, and E. Lulekal, "Floristic composition of and structure of the dry Afromontane forest at Bale Mountains National Park, Ethiopia," SINET: Ethiopian Journal of Science, vol. 31, no. 2, pp. 103-120, 2008.

[27] E. Lulekal, Z. Asfaw, E. Kelbessa, and P. Van Damme, "Ethnomedicinal study of plants used for human ailments in Ankober District, North Shewa Zone, Amhara Region, Ethiopia," Journal of Ethnobiology and Ethnomedicine, vol. 9, article 63, 2013.

[28] N. Amsalu, Z. Asfaw, and E. Kelbessa, "An ethnobotanical study of medicinal plants in Farta District, South Gondar Zone of Amhara Region, Ethiopia," pp. 28-55, Haddis Alemayehu Institute of Cultural Studies, Debre Markos University, Ethiopia, 2015.

[29] M. Giday, Z. Asfaw, and Z. Woldu, "Medicinal plants of the Meinit ethnic group of Ethiopia: an ethnobotanical study," Journal of Ethnopharmacology, vol. 124, no. 3, pp. 513-521, 2009.

[30] S. Getaneh, Ethnobotanical study of medicinal plants in Debrelibanos wereda, North Shewa Zone of Oromia Region, Ethiopia [Thesis], Addis Ababa University, Addis Ababa, Ethiopia, 2009.

[31] G. Gebeyehu, Z. Asfaw, A. Enyew, and N. Raja, "An Ethnobotanical Study of Traditional use of medicinal plants and their conservation status in Mecha Wereda, West Gojjam zone of Amhara Region, Ethiopia," Ethiopia International Journal of Health Research, vol. 02, no. 03, pp. 137-154, 2014.

[32] E. Tolasa, Use and Conservation of Traditional Medicinal Plants by Indigenous People in Gimbi Wereda, Western Wellega [Thesis], Addis Ababa University, Addis Ababa, Ethiopia, 2007.

[33] E. Lulekal, E. Kelbessa, T. Bekele, and H. Yineger, "An ethnobotanical study of medicinal plants in Mana Angetu District, southeastern Ethiopia," Journal of Ethnobiology and Ethnomedicine, vol. 4, article 10, 2008.

[34] F. Mesfin, S. Demissew, and T. Teklehaymanot, "An ethnobotanical study of medicinal plants in Wonago Woreda, SNNPR, Ethiopia," Journal of Ethnobiology and Ethnomedicine, vol. 5, no. $28,2009$. 
[35] K. N. Singh and B. Lal, "Ethnomedicines used against four common ailments by the tribal communities of Lahaul-Spiti in western Himalaya," Journal of Ethnopharmacology, vol. 115, no. 1, pp. 147-159, 2008.

[36] T. Awas and S. Demissew, "Ethnobotanical study of medicinal plants in Kafficho people, southwestern Ethiopia," in Proceedings of the 16th International Conference of Ethiopian Studies, S. Ege, A. Harald, B. Teferra, and S. Bekele, Eds., pp. 711-726, Trondheim, Norway, 2009.

[37] A. Belayneh, Z. Asfaw, S. Demissew, and N. F. Bussa, "Medicinal plants potential and use by pastoral and agro-pastoral communities in Erer Valley of Babile Wereda, Eastern Ethiopia," Journal of Ethnobiology and Ethnomedicine, vol. 8, article 42, 2012.

[38] B. Etana, Ethnobotanical study of traditional medicinal plants of Goma Wereda, Jima Zone of Oromia Region, Ethiopia [Thesis], Addis Ababa University, Addis Ababa, Ethiopia, 2010.

[39] T. Teklehaymanot and M. Giday, "Ethnobotanical study of medicinal plants used by people in Zegie Peninsula, Northwestern Ethiopia," Journal of Ethnobiology and Ethnomedicine, vol. 3, article 12, 2007.

[40] A. Getahun, Some Common Medicinal and Poisonous Plants Used in Ethiopian Folk Medicine, Addis Ababa University, Addis Ababa, Ethiopia, 1976.

[41] D. Abebe, "Traditional medicine in Ethiopia. The attempt being made to promote it for effective and better utilization," SINET: Ethiopia Journal of Science, vol. 9, pp. 61-69, 1986.

[42] M. Heinrich, A. Ankli, B. Frei, C. Weimann, and O. Sticher, "Medicinal plants in Mexico: healers' consensus and cultural importance," Social Science \& Medicine, vol. 47, no. 11, pp. 18591871, 1998.

[43] H. Reta, An Ethnobotanical Study of Useful Plants of the Farming Site in Gozamin Wereda, East Gojjam Zone of the Amhara Region, Ethiopia [Thesis], Addis Ababa University, Addis Ababa, Ethiopia, 2010.

[44] J. L. Vivero, E. Kelbessa, and S. Demissew, "Progress on the red list of plants of Ethiopia and Eritrea: Conservation and biogeography of endemic flowering taxa," in Taxonomy and Ecology of African Plants, Their Conservation and Sustainable Use, S. A. Ghazanfar and H. J. Beentje, Eds., pp. 761-778, 2006, Proceedings of the 17th AETFAT congress, Addis Ababa, Ethiopia. 


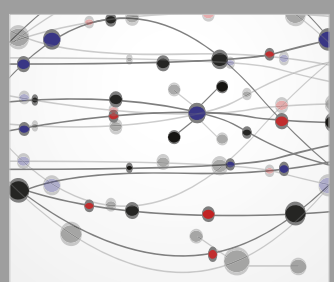

The Scientific World Journal
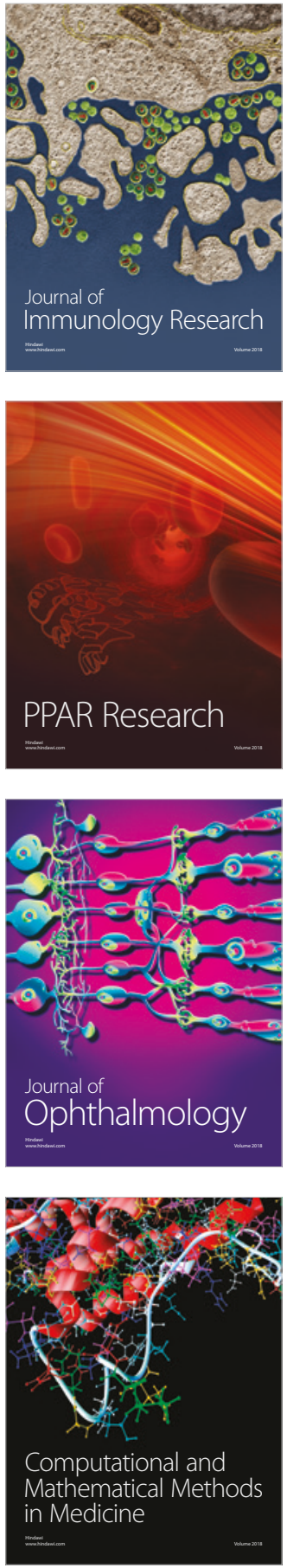

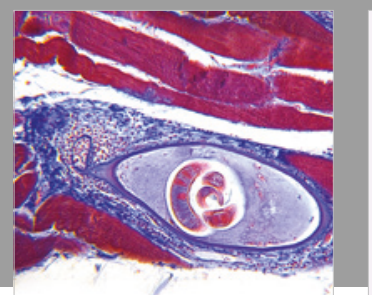

Gastroenterology Research and Practice

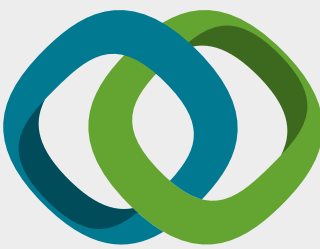

\section{Hindawi}

Submit your manuscripts at

www.hindawi.com
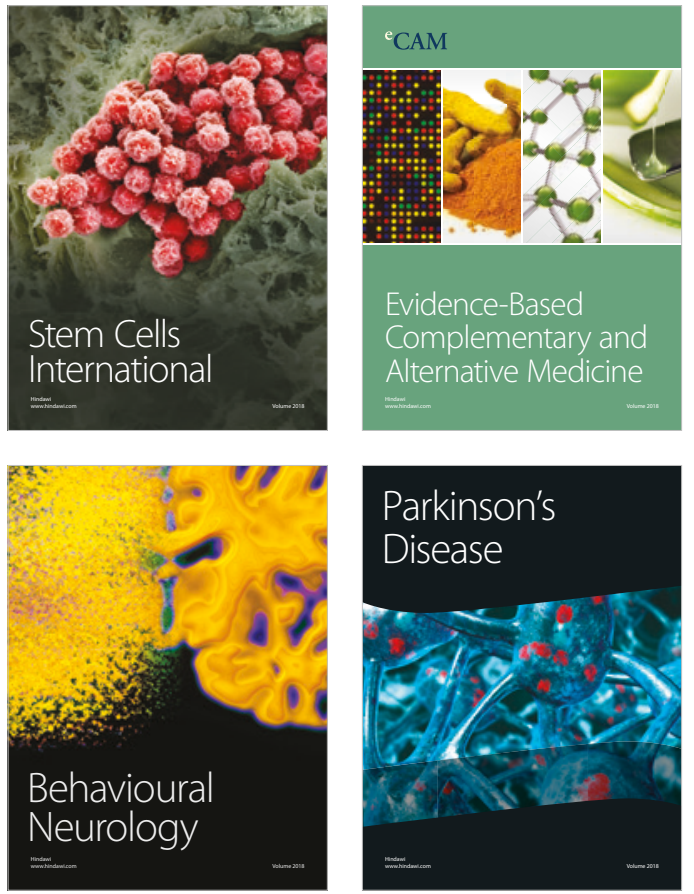

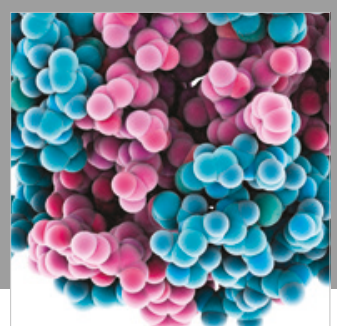

ournal of

Diabetes Research

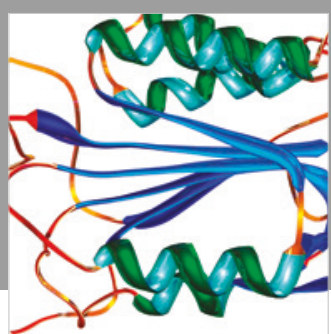

Disease Markers
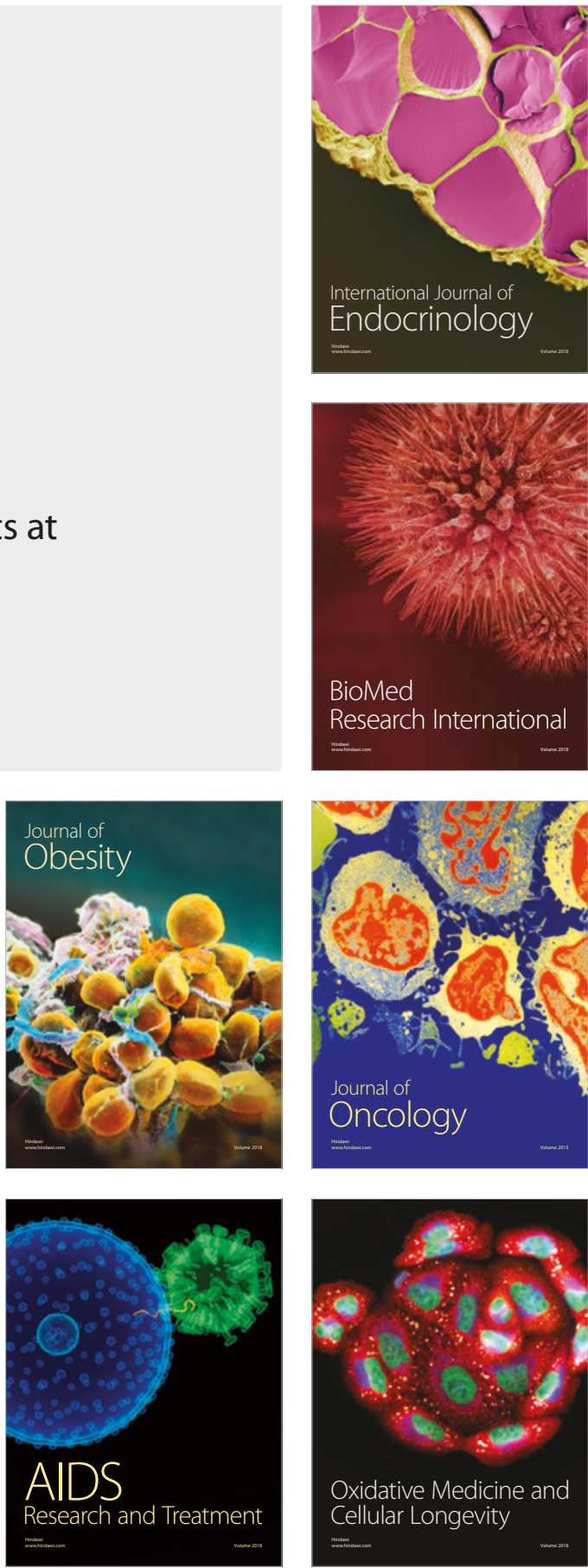